\title{
La entrega extraordinaria y la desaparición forzada a la luz del Derecho penal y el Derecho internacional de los Derechos Humanos*
}

John A. E. Vervaele**

\section{Resumen}

Tras los atentados del once de septiembre, el gobierno de los Estados Unidos de América emprendió una lucha contra el terrorismo prevalido de sus propios métodos; por ello, con la colaboración de diversas naciones, sobre todo europeas, llevó a cabo un programa de entregas extraordinarias de sospechosos a quienes, en secreto y sin orden judicial alguna, se privó de la libertad, desapareció, torturó y recluyó en cárceles e instalaciones destinadas a tales efectos, como la base de Guantánamo. En el artículo se examinan estos hechos a la luz del derecho internacional de los derechos humanos.

\section{Palabras clave}

Derecho internacional, derechos humanos, derecho penal, desaparición forzada, detención preventiva, entrega extraordinaria, orden judicial, Guantánamo, Informe Feinstein, seguridad, terrorismo, torturas.

\footnotetext{
El presente trabajo es una traducción de la versión actualizada del texto de mi autoría publicado con el título: Extraordinary Rendition and Transnational Forced Disappearance under Criminal Law and the IHRL. En M. Caianiello \& M. L. Corrado (eds.), Preventing Danger. New Paradigms in Criminal Justice. Durham-North Carolina: Carolina Academic Press, 2013, 167-206.

* Ph. D. Catedrático de Derecho Penal Económico y Europeo de la Universidad de Utrecht, Holanda; profesor de Derecho Penal Europeo del Colegio de Europa/Brujas, Bélgica. El autor agradece sinceramente a Stefhanie Cisneros Salazar por la traducción y al catedrático Fernando Velásquez Velásquez por la supervisión de ella.
} 


\title{
Extraordinary Rendition and Enforced Disappearance in the Light of Criminal Law and International Law of Human Rights
}

\begin{abstract}
After Sept. 11 attacks, the government of the United States of America launched a fight against terrorism availed by its own methods; therefore, with the collaboration of various nations, especially European, it carried out a program of extraordinary renditions of suspects who, in secret and without a warrant, were deprived of liberty, disappeared, were tortured and detained in prisons and facilities intended for such purposes as those of Guantanamo Bay. In this article these facts are examined in the light of international law of human rights.
\end{abstract}

\section{Keywords}

International law, human rights, criminal law, enforced disappearance, pretrial detention, extraordinary rendition, court order, Guantanamo, Feinstein report, security, terrorism, torture. 


\section{De la detención preventiva a la detención por razones de seguridad}

En las últimas décadas, los objetivos de la detención preventiva se han ampliado de tal forma que ella ha pasado de ser una medida de defensa social a convertirse en un instrumento para la protección de la seguridad (nacional), especialmente en el ámbito de la lucha contra el terrorismo. Adicionalmente, la figura comentada ha sido desvinculada de la justicia penal y del juicio.

Anticipar el riesgo se ha convertido en una fuerza impulsora de la justicia penal; tanto es así, que se ha integrado la seguridad nacional en esa justicia penal (Hirsch, 2012). De esta manera, la detención por razones de seguridad se ha tornado en una medida de detención preventiva [Sicherungsverwahrung] o detención de los individuos etiquetados como un peligro para el orden público, la seguridad pública o la seguridad nacional, debido a su conducta o incluso a su perfil (Nikos, 2011; Posl, 2011). La versión más extrema de este instrumento ha sido, sin duda, las prácticas de la CIA que fueron bien detalladas en el Informe del Senado de Estados Unidos (Feinstein, 2014).

El cambio de paradigma también afecta a la cooperación internacional en materia penal. Tradicionalmente, la colaboración entre los Estados o las autoridades judiciales relacionada con el arresto y la detención de las personas, en lo que toca con el objetivo de entregas en materia penal -cuando hay actuaciones en contra de los requeridos o se hace necesaria la ejecución de las condenas penales ya emitidas-, se regulaba y aplicaba a través de tratados mutuos de asistencia legal(MLAT) de carácter bilateral o multilateral, en especial los llamados tratados bilaterales y multilaterales de extradición (Bassiouni, 2007). Los MLAT también contienen garantías contra la extradición arbitraria como, por ejemplo, aquellas según las cuales la solicitud de extradición tiene que ser de carácter judicial y basada en motivos razonables de los cuales se infiera que una persona ha cometido un delito extraditable, tanto en el país requirente como en el requerido (principio de la doble incriminación).

Aunque los MLAT tenían por objeto exclusivamente el arresto transfronterizo y la detención y la entrega de personas sospechosas o condenadas, algunos países también han puesto en marcha políticas de entrega o de extradición administrativa o ejecutiva (sin participación en absoluto del poder judicial). Esa entrega a la justicia puede ser descrita como una técnica mediante la cual una 
persona sospechosa es aprehendida forzosamente en otro Estado, cuando es imposible llevarla para ser juzgada por el procedimiento de extradición normal. Esto significa que la entrega solo se aplica cuando exista una orden de detención pendiente en contra de la persona y con el objetivo de hacerla pasible de una medida penal por parte del Estado que la requiere (Nadelmann, 1993, pp. 857-852). La retención forzosa puede ejecutarse de manera unilateral por parte de los agentes del foro estatal o con la colaboración de funcionarios estatales del Estado en el que se aprehendió a la persona. La entrega, en relación con la política de justicia, se encuentra basada en la ley estatutaria nacional y, hasta cierto punto, está sometida a revisión judicial administrativa por parte de los tribunales. Una vez que la persona se encuentra en el foro del estado, ella es sometida a la justicia penal ordinaria como cualquier otro detenido a la espera de juicio. Esto último se lleva a cabo mediante un proceso judicial, debido a que la persona es aprehendida por razones de justicia penal: para comparecer ante la justicia en virtud de una actuación en marcha o para ejecutar una condena ya proferida. Esto no significa que la entrega en sí misma sea un procedimiento judicial, dado que carece de una orden judicial y, en realidad, supone casi siempre un operativo militar o policial encubierto, con el riesgo de infringir la soberanía estatal de otros estados (en función de la cooperación con el Estado).

El secuestro de Adolf Eichmann por el Mossad en 1960 en Argentina, con motivo de su entrega a la justicia en Israel, fue sin duda uno de los primeros y más famosos casos de entrega forzada. Esta práctica ha sido parte de una política direccionada por los Estados Unidos durante décadas y se remonta más atrás en la historia; en efecto, ella fue aprobada para su uso contra los sospechosos de terrorismo por parte de Ronald Reagan en 1986 (Cameron, 1998), aunque también se utilizó en casos de drogas o de tráfico de armas. El secuestro del expresidente Manuel Antonio Noriega en la ciudad de Panamá, por las fuerzas militares de los Estados Unidos para enfrentar un juicio en este último país por los cargos de tráfico de drogas, es el ejemplo más notorio de esta práctica (Tribunal del Distrito de los Estados Unidos, Estados Unidos vs. Noriega, 1990).

Así mismo, en 1993, George H. W. Bush autorizó procedimientos específicos para la entrega a través de la Directiva de Seguridad Nacional $77^{1}$. También Bill Clinton firmó, en 1988, la Directiva 
de Decisión Presidencial 62, que daba libertad de acción a varios programas antiterroristas, incluyendo el de Detención, Extradición, Entrega y Persecución ${ }^{2}$. Aunque el secuestro en territorios donde rige la soberanía extranjera para hacer la entrega de las personas a la justicia es ilegal según el derecho internacional, el Tribunal Supremo de los EE.UU. ratificó la competencia del gobierno para procesar a las personas secuestradas, independientemente de la legalidad de este procedimiento en el derecho internacional, excluyendo también la aplicación de las normas constitucionales de Estados Unidos a sus agentes cuando actúan fuera del territorio estadounidense (la doctrina Kerr-Frisbie/Alvarez-Machain) (Véase, Estados Unidos vs. Álvarez-Machain, 1992; Frisbie vs. Collins, 1952; Ker vs. Illinois, 1886; Stark, 1993, p. 161).

Diversos países europeos, por ejemplo Francia y España, practicaron la misma política como parte de su estrategia antiterrorista contra personas sospechosas de estar involucradas en actividades de Patria y Libertad Vasca (ETA). La llamada 'extradición administrativa' se aplicó con el fin de eludir los engorrosos y largos procedimientos de extradición y, también, para esquivar las garantías de las disposiciones de los MLAT sobre extradición. Dicha política se ejecuta, entonces, bajo el esquema de la cooperación policial informal y sin ningún marco legal. En la práctica, las autoridades policiales y oficiales de inteligencia entregaban a la persona en cuestión, en las fronteras del Estado requirente, a las autoridades extranjeras. En aquel entonces, hubo, sin embargo, una diferencia sustancial con la entrega prescrita para la política de justicia de los EE.UU. En los países europeos, la extradición administrativa fue el resultado de la cooperación bilateral entre las autoridades policiales y de inteligencia de los Estados. En cambio, en los EE. UU., la entrega a la justicia fue el resultado de un secuestro de personas unilateral y extraterritorial cometido por parte de oficiales estadounidenses en un territorio extranjero.

Otro ejemplo reciente en la práctica de la entrega a la justicia se aplicó de forma sistemática en el área de Somalia-Golfo de Adén, para hacer frente a la persecución de la piratería. Algunos de los acusados terminaron en juicios penales en los estados europeos sin ningún procedimiento de extradición (Geiss \& Petrig, 2011, p. 344). Precisamente, durante la presidencia de B. Clinton, los procedimientos para la entrega a la justicia fueron cambiados. Varias personas fueron capturadas y secuestradas por los militares 
de los Estados Unidos en la década de 1990 en Bosnia y Albania y trasladadas a Egipto. El primer caso conocido de este tipo de entrega fue el de 'Tal'at Fu'ad Qassim', aprehendido de forma ilegal en Bosnia y transferido a un buque de la Armada de EE. UU. para ser interrogado y llevado a Egipto donde posteriormente sería detenido y sometido a interrogatorio. Qassim fue, según se informa, ejecutado mientras estaba bajo custodia egipcia (Human Rights Watch, 2005).

La entrega a la justicia se convirtió así, en el gobierno de Clinton, en una aprehensión de personas para interrogarlas y recopilar medios de inteligencia; en régimen de detención de seguridad. El exdirector de la CIA, George Tenet, estimó que la Agencia había secuestrado a más de 80 personas antes del 11 de septiembre de $2011^{3}$. Esto significa que el gobierno de Clinton transformó la política de entrega a la justicia, que, de ser una técnica de aplicación de la ley penal, se convirtió en un objetivo preventivo. Así las cosas, la entrega de personas a la justicia se transformó en una aprehensión de las mismas al servicio de las políticas de seguridad. Así, pues, nació la entrega extraordinaria (Johnson, 2009, p. 1136; Satterthwaite, 2007, p.1372).

La CIA, en colaboración con el Departamento de Defensa y el FBI, se hicieron responsables de un programa de lucha contra el terrorismo mediante el cual el Estado (patrocinador) produjo el secuestro de personas en países extranjeros. Estas personas fueron raptadas por agentes de los Estados Unidos, con o sin la cooperación del gobierno del respectivo país, y, con posterioridad, fueron trasladadas a otras naciones para su detención e interrogatorio. A pesar de los artículos en el Washington Post, en 2002, sobre la práctica de la externalización de los interrogatorios de los terroristas, no fue sino hasta el 2006, a raíz de la sentencia del Tribunal Supremo sobre Hamdan vs. Rumsfeld, que la existencia del programa de entregas extraordinarias fue confirmada por George W. Bush (hijo). Él lo denominó como un mecanismo independiente operado por la CIA para detener e interrogar tanto a personas sospechosas de ser los principales artífices de los atentados del once de septiembre, los ataques en el USS Cole y los bombardeos de las embajadas de Estados Unidos en Kenia y Tanzania, como a personas envueltas en otros ataques que han costado la vida de civiles inocentes en todo el mundo. Admitió públicamente lo que se había sospechado desde hacía mucho tiempo: que el gobierno de los EE.UU. administraba un programa mundial de detención secreta de com- 
batientes enemigos. Una directiva presidencial, firmada el 17 de septiembre de 2001, le dio potestades legales a la CIA para ejecutar el programa de entregas extraordinarias (Véanse, Extraordinary rendition in U.S. counterterrorism policy: the impact on transatlantic relations, 2007; Protection Against Unconventional Threats to the Homeland and Americans Overseas, 1998; U.S. Policy on Counterterrorism, 1995).

Después dela sentencia del TribunalSupremoen el asunto Hamdan vs. Rumsfeld, el Congreso aprobó en el 2006 la Ley de Comisiones Militares, proporcionando así una base legal para detener, interrogar y tratar a los 'combatientes enemigos ilegales'. El gobierno de Bush (hijo) presentó la Ley de Comisiones Militares como base jurídica suficiente para el programa de entregas extraordinarias, aunque las cláusulas específicas en la Ley son insuficientes y no es seguro que todas las personas secuestradas sean formalmente etiquetadas como 'combatientes enemigos ilegales'. Es más, el gobierno de Obama se comprometió a examinar la práctica de las entregas extraordinarias, pero no la llevó a su fin y tampoco la formalizó como una política encubierta de combatientes enemigos.

Aunque la entrega a la justicia y la entrega extraordinaria, son medidas administrativas especiales (special administrative measures, SAM), con tal proceder se desvían esos dos mecanismos del procedimiento de extradición judicial ordinario para ponerle el calificativo de 'extraordinario' en el frente de la ejecución y cambiar, así, fundamentalmente su significado. De esta manera, un proceso antiguamente obligado por la ley estatutaria y los tratados y reforzado por garantías procesales ante los tribunales, había entrado en el reino de la política ejecutiva discrecional. En los EE.UU., el ejecutivo etiquetó a la entrega extraordinaria como la transferencia de combatientes enemigos, por lo que al Presidente se le consideró exonerado de las limitaciones ex ante previstas en la ley y en la Constitución nacional, al otorgarle competencia para transferir a los detenidos fuera de los EE.UU. y ponerlos bajo la custodia de las naciones extranjeras (Yoo, 2003, p. 1184).

\section{Entregas extraordinarias: casos y cifras}

La práctica de las entregas extraordinarias era bastante desconocida hasta los años 2005-2006 y fue gracias a investigaciones formales, consultas informales (tanto por la prensa como por las organizaciones no gubernamentales) y al control político en Europa 
(Dick Marty, 2003; Parlamento Europeo, s.f.; Parlamento Europeo, 2007) como se pudo aclarar el alcance y la magnitud de semejante programa. El número exacto de casos no está claro, pues, como las fuentes lo indican, van desde varios cientos a varios miles. Desde luego, debe tenerse en cuenta que los eventos en los cuales los estados europeos se han visto involucrados están ampliamente documentados, no así aquellos practicados en la región asiática, que son raramente conocidos.

Con el objetivo de visualizar la susodicha práctica del sistema de entrega extraordinaria, me gustaría mencionar aquí tres sucesos emblemáticos en los cuales los países europeos han participado: los caos de Hassan Mustafa Osama Nasr, Khaled El-Masri y Al Nashiri.

Con respecto al primero, debe decirse que Hassan Mustafa Osama Nasr, también llamado Abu Omar, era un musulmán de ascendencia egipcia que se desempeñaba como Imán en Milán y de quien se sospechaba que contribuía a radicalizar a la comunidad musulmana. Dicho ciudadano fue secuestrado en 2003, gracias a un operativo conjunto realizado entre agentes de la CIA y de la inteligencia italiana, y fue trasladado a Egipto a través de un aeropuerto militar en Alemania. En Egipto, fue recluido en secreto durante dos meses y, luego, estuvo bajo arresto domiciliario por casi cuatro años en los cuales fue sometido a interrogatorios y, se sospecha, que también fue torturado; después, se le dejó en libertad sin que mediara ninguna orden de detención, acusación o procedimiento de hábeas corpus.

Los autores del secuestro fueron juzgados en Italia por varios delitos, después de que las autoridades judiciales de Milán establecieran su identidad durante una investigación judicial a fondo, que condujo a la detención de los oficiales de inteligencia italiana y a la solicitud de extradición de los agentes de la CIA involucrados. Sin embargo, esa petición nunca fue enviada por el ejecutivo italiano a los EE.UU. (y ello sucedió tanto en el gobierno de Prodi como en el de Berlusconi).

De esta manera, entonces, el gobierno de Berlusconi usó la inmunidad en asuntos de interés público de Secreto de Estado con el fin de evitar el uso de las pruebas obtenidas en los locales de las autoridades de inteligencia (Illuminati, 2010). El Tribunal Constitucional italiano aprobó el uso del privilegio ejecutivo, que excluía una 
parte sustancial de las pruebas de la fase de enjuiciamiento. Luego, en noviembre de 2009, el Tribunal de Milán condenó a 22 agentes de la CIA, a un piloto de la Fuerza Aérea y a dos agentes secretos italianos, al hallarlos responsables por la entrega extraordinaria de Abu Omar en suelo italiano, y les impuso penas de prisión de hasta ocho años a los dirigentes de esas operaciones. Sin embargo, algunos de los acusados no fueron condenados debido a la inmunidad diplomática. En septiembre de 2012, el Tribunal Supremo italiano confirmó las condenas por la entrega extraordinaria en contra de los 22 agentes de la CIA, el piloto de la Fuerza Aérea y los agentes secretos italianos involucrados y dispuso, además, que los agentes secretos italianos previamente absueltos con base en las inmunidades propias del secreto de Estado debían ser juzgados por el Tribunal de Apelación de Milán. De esta forma, el juicio penal italiano y las condenas han sido las primeras, y hasta ahora las únicas, en contra de las personas involucradas en el programa de entrega extraordinaria de la CIA.

El segundo caso es el de Khaled El-Masri primero, un musulmán de ascendencia libanesa nacido en Kuwait y quién es también ciudadano de Alemania -país este último al que se trasladó desde 1985-. En el 2003, El-Masri viajó a Skopje en Macedonia a disfrutar de unas breves vacaciones. En la frontera, fue detenido por las autoridades de inteligencia local, que lo interrogaron durante varias horas y luego lo llevaron a un hotel, donde estuvo detenido durante 23 días bajo vigilancia armada, sin una orden de detención ni acceso a un abogado; tampoco fue objeto de alguna acusación y se le sometió a diversos actos posteriores mediante los cuales se le violentaron todos sus derechos. Fue interrogado de forma continua; incluso las autoridades locales de Macedonia, las alemanas municipales y de policía, intercambiaron información sobre él durante el interrogatorio. Después de la detención, fue trasladado al aeropuerto de Skopje y se le entregó a un grupo de agentes de la CIA. El avión voló a Afganistán, donde se le mantuvo en detención secreta durante otros cuatro meses, hasta que las autoridades descubrieron que probablemente era la persona equivocada, dado que él tenía un nombre similar al de un hombre vinculado a una 'célula de Hamburgo' del movimiento Al-Qaeda.

En vista del error cometido y con el fin de encubrirlo, ElMasri fue trasladado en avión de regreso a Albania gracias a una 'entrega extraordinaria inversa'. En Macedonia, las investigaciones administrativas y penales se abrieron, pero como resultado de 
los pocos progresos, las mismas tuvieron que ser archivadas en atención a las barreras legales de tiempo. No obstante, en 2004, un Fiscal alemán de Múnich abrió una investigación formal en relación con las denuncias en las cuales se daba cuenta de que El-Masri había sido ilegalmente secuestrado y detenido, así como psíquica y psicológicamente maltratado e interrogado en Macedonia y Afganistán.

Gracias a ello, en el 2005, fueron enviadas cartas rogatorias a Macedonia y, en el 2007, se emitieron órdenes internacionales de arresto contra trece presuntos agentes de la CIA y/o personal de la misma agencia. Las autoridades macedonias se negaron a cooperar y las autoridades ejecutivas alemanas no quisieron enviar las solicitudes de extradición a los Estados Unidos. Durante los procedimientos civiles en los EE.UU., y bajo el Estatuto de reclamación por agravios contra extranjeros, El-Masri fue confrontado con el uso del privilegio de secretos de Estado por el gobierno de EE.UU. Tanto el Tribunal de Distrito como el Tribunal de Apelaciones del Cuarto Circuito decidieron que el caso no podía ser expuesto sin revelar secretos de Estado. El Tribunal Supremo no estaba dispuesto a revisar el caso. La ONG Unión Estadounidense por las Libertades Civiles presentó una petición ante la Comisión Interamericana de Derechos Humanos (CoIDH) en el 2008. Por su parte, la Fundación Soros presentó en el 2009 una petición ante el Tribunal Europeo de Derechos Humanos (TEDH) en contra de Macedonia, que sigue a la espera del dictamen oficial por parte de los EE.UU. En este último evento, la Gran Cámara del TEDH ha emitido su fallo el día trece de diciembre de $2012^{4}$.

El tercer caso que podría exponerse como un ejemplo claro de este tipo de políticas, es el del ciudadano saudí Al Nashiri detenido en Dubai, en el año 2002, por las autoridades locales y quien, luego de un mes de privación de la libertad, fue traslado también en forma secreta y puesto bajo la custodia de la CIA que lo envió a una prisión conocida como Salt pit en Afganistán. Allí, se le interrogó intensamente e, incluso, existen sospechas de que fue sometido a actos de tortura; luego de una corta estadía ahí, Al-Nashiri fue transferido por la misma CIA a una prisión secreta en Bangkok y, en breve tiempo, fue objeto de traslado a otra prisión secreta de Polonia. Posteriormente, la CIA lo sometió a más detenciones en un número de localizaciones secretas fuera de Polonia para, seguidamente, conducirlo a Rabat, en Marruecos, y después a Guantánamo. 
Luego de un año de permanencia en esta última sede, fue enviado de regreso a Rabat y, con posterioridad, conducido a Bucarest, en Rumania. En 2006 fue llevado nuevamente a Guantánamo; no obstante, solo en septiembre de ese año la administración de los EE.UU. se entera de que la CIA lo había detenido en secreto fuera del país y que, desde aquel entonces, había sido transferido a la custodia de los EE.UU. en la Bahía de Guantánamo. Es más, en 2009 se le imputaron diversos cargos frente a una Comisión Militar de Guantánamo, los mismos que luego fueron retirados a la espera de la anunciada revisión de todas las detenciones practicadas en esa Bahía por parte de la administración del Presidente Obama; en la actualidad, Al-Nashiri se encuentra sometido a juicio por parte de un Tribunal Militar de Guantánamo; el 20 de abril del 2011 los fiscales militares pidieron la imposición de la pena de muerte en su contra.

A raíz de lo explicado, la Fundación Soros presentó, en 2009, una petición ante el TEDH contra Polonia y, en 2012, contra Rumania y Lituania, en ambos casos para que el Tribunal Europeo de Derechos Humanos se pronunciara sobre estos hechos; gracias a ello, el TEDH emitió una sentencia condenatoria contra Polonia el 24 de julio 2014, por haber permitido en su territorio interrogatorios y retenciones secretas por parte de la CIA (TEDH, Nashiri vs. Polonia, 2014). Aun así, lo que está claro es que Al-Nashiri lleva cerca de 10 años privado injustamente de su libertad en Guantánamo.

Con todo lo expuesto, es evidente que el papel de los estados europeos y de los agentes $\mathrm{u}$ oficiales de dichos estados en el programa de entrega extraordinaria, puede adoptar varias formas que van desde el secuestro de personas, su traslado, el establecimiento y uso de centros de detención secreta, o incluso ciertos tipos de facilitación del programa (a través del intercambio de información de inteligencia o facilitando los vuelos secretos de la CIA, y así sucesivamente). De esta manera, varios estados europeos han orquestado, cooperado o facilitado el programa de entrega extraordinaria, lo que ha derivado en un tema político muy sensible, sobre todo por la evidente y ya comprobada participación de los estados europeos en ese programa.

\section{Control político en Europa}

El Parlamento de la Unión Europea creó en el año 2007 la 'Comisión Temporal sobre la supuesta utilización de Países Europeos 
por parte de la CIA para la transportación y detención ilegal de prisioneros'. El objetivo de la misma era determinar si la CIA había realizado detenciones secretas o entregas extraordinarias en territorio europeo, o si usó ese territorio para contribuir al desarrollo de dichas actividades y evaluar si los ciudadanos europeos o incluso los estados miembros de la Unión Europea estaban relacionados con esas actividades delictivas. En febrero de 2007 fue publicado el reporte del eurodiputado italiano Claudio Fava ante el Parlamento Europeo, el cual contenía información detallada sobre algunas de las operaciones y la cooperación prestada por los países europeos y sus agentes, en su mayoría verificadas en el archivo civil y de inteligencia militar y en el archivo de transporte militar.

De esta forma, el Consejo del Parlamento Europeo, realizó dos consultas separadas a los Estados. En primer lugar, a través de su Secretario General, Terry Davis, les solicitó que bajo el artículo 57 de la Convención Europea de Derechos Humanos (CEDH), explicaran cómo aseguraban que los agentes extranjeros estuvieran sujetos a controles adecuados en su territorio, así como las medidas que se tomaron para prevenir las detenciones secretas y cómo aseguraron que se estaban llevando a cabo investigaciones efectivas. De esta manera, se hizo evidente en el reporte que en muchos estados faltaban acuerdos legales que regularan esas actividades (Consejo Europeo: Secretaria General, 2006); por ejemplo, el régimen para el tráfico aéreo era inadecuado y las reglas de inmunidad eran un obstáculo claro para llevar a cabo investigaciones efectivas.

La segunda consulta fue realizada por el Comité en asuntos legales y Derechos Humanos de la Asamblea Parlamentaria, bajo la dirección del reportero Dick Marty, quién produjo dos reportes, uno en el año 2006 y otro en 2007 (Asamblea Parlamentaria, 2006 y 2007). Dick Marty ha tenido mucho éxito al destapar las rutas de vuelo de la CIA en sus viajes a Europa de manera concreta, lo que de igual forma permitió ver la relación de las autoridades nacionales europeas en la transferencia ilegal de las personas detenidas.

En virtud de su competencia como Presidente del Comité de asuntos legales y Derechos Humanos de la Asamblea Parlamentaria del Consejo Europeo, Dick Marty solicitó también a la Comisión Europea para la democracia, a través del Derecho (Comisión de Venecia), una opinión legal sobre las obligaciones de carácter internacional de los Estados miembros del Consejo Europeo en 
relación con las facilidades que se brindaban para las detenciones secretas y el transporte interestatal de prisioneros. La Comisión de Venecia adoptó su reporte en el año 2006 y concluyó que los Estados implicados en operaciones de entregas extraordinarias habían obrado incumpliendo el derecho internacional y habían incurrido en violación de los estándares aplicables en materia de derechos humanos. Lo anterior pudo darse gracias a las distintas formas de participación en dichas actividades o por no cumplir satisfactoriamente y de manera positiva con las obligaciones de investigar, enjuiciar y sancionar (Consejo de Europa, 2006).

Finalmente, en el año 2007, el Comité de Inteligencia y Seguridad del Reino Unido publicó un reporte bastante crítico en relación con las entregas. El objetivo era determinar si las agencias de inteligencia y seguridad de esa nación habían tenido conocimiento de la participación de sus servidores en las operaciones de entrega. El Comité consideró en sus recomendaciones que las detenciones secretas sin representación legal o de otro tipo, son de por sí malos tratos (Murphy, 2007); y, en su opinión, cuando existe la posibilidad real de 'rendición de detención' para una instalación secreta, por un tiempo limitado, la aprobación no debe ser dada. No obstante, no encontró evidencia alguna acerca de la complicidad de las agencias del Reino Unido en operaciones de 'entregas extraordinarias', pero sí fue bastante crítico acerca de la creación de las entregas extraordinarias en lugar de las 'entregas a la justicia', las 'entregas militares' y las 'entregas para la detención', las cuales son y se mantienen para el Comité como herramientas justificables de la inteligencia civil y militar.

\section{Las entregas extraordinarias bajo las normas del Derecho Internacional de los Derechos Humanos}

Tanto la entrega a la justicia como la entrega extraordinaria, no son términos legales existentes en el derecho internacional. Cuando se trata de una evaluación de la práctica de la entrega extraordinaria en virtud de las normas internacionales de derechos humanos, tenemos que enfrentarnos a un conjunto híbrido de posibles violaciones de los mismos, tales como el arresto arbitrario y la detención, las desapariciones y el desplazamiento forzados, la tortura, la negación de acceso a las oficinas consulares, la proscripción de acceso a tribunales independientes e imparciales, etc. En este trabajo, me gustaría centrarme en la detención secreta 
como método y objetivo del programa de entregas extraordinarias y hacer frente a la cuestión de si, y en qué medida, los instrumentos de normas internacionales de derechos humanos aceptan una categoría específica de detención por razones de seguridad, especialmente en el ámbito de la lucha contra el terrorismo. Una cuestión relacionada con esta es si las normas internacionales de derechos humanos aplican regulaciones específicas para la extradición o la entrega a la justicia y de entrega extraordinaria (medidas administrativas especiales) en ese sentido.

Como nos enfrentamos aquí, desde el punto de vista europeo, con una práctica transnacional constitutiva de una verdadera empresa criminal conjunta entre oficiales y agentes de Estados Unidos y de países europeos, me gustaría enfocarme en algunos problemas específicos y complejos comunes a todos estos estándares. El primer asunto a proponer es el siguiente: ¿tienen jurisdicción los estados europeos desde el punto de vista del Derecho Internacional de los Derechos Humanos (DIDH)? En otras palabras: ¿los tratados de derechos humanos se aplican en este tipo de situaciones? Debe advertirse que este asunto es de particular importancia, en vista de que la Corte Suprema de los Estados Unidos no está dispuesta a aplicar los estándares constitucionales propios para los agentes que actúan fuera del territorio estadounidense (así, la 'Doctrina: KerrFrsibie/Alvaréz-Machain').

Ahora bien, el siguiente asunto que amerita mayor análisis es la cuestión de si el DIDH acepta una categoría específica de detenciones de seguridad, especialmente en el campo de la lucha contra el terrorismo, y, si es así, cuán amplia sería. De igual forma, la tercera pregunta se planteará en torno al DIDH, pero esta vez en cuanto a la aplicación de estándares específicos para la extradición o la entrega a la justicia/entrega extraordinaria (medidas administrativas especiales, por sus siglas en inglés: SAM).

\section{Jurisdicción.}

La mayoría de convenciones de derechos humanos, incluyen efectivamente estándares universales; sin embargo, ello no significa que los estados deban aplicarlos en todas las situaciones ni que serán encontrados responsables en todos los casos. En otras palabras: los estados deben tener jurisdicción para ser encontrados responsables. La mayoría de los tratados en materia de derechos humanos inician 
en sus primeros artículos con referencias a los individuos sujetos a su jurisdicción, pero sin definirlos. La jurisdicción está tradicionalmente relacionada con la aplicación territorial del derecho internacional, sin embargo se ha dado una importante evolución cuando se trata de la aplicación del DIDH.

\section{Pacto internacional de los derechos civiles y politicos/ El Comité de Derechos Humanos.}

Desde 1981, el Comité de Derechos Humanos, creado en virtud del artículo 28 del Pacto Internacional de los Derechos Civiles y Políticos (PIDCP), trató el asunto en el caso de Lilian Celiberti de Casariego vs. Uruguay (Comité de Derechos Humanos, 1981). En 1978, dicha dama fue arrestada en Porto Alegre (Brasil) junto con sus dos hijos y el señor Universindo Rodríguez Díaz. El arresto fue llevado a cabo por agentes uruguayos con la complicidad de dos oficiales de policía brasileños. Durante una semana, Celiberti junto con los demás retenidos, permanecieron privados de su libertad en el apartamento de la referida señora en Porto Alegre y, luego, fueron llevados a la frontera Uruguaya. De esta forma, fueron secuestrados y conducidos de manera forzada dentro del territorio uruguayo, donde los mantuvieron detenidos. Una semana después, las Fuerzas Conjuntas de Uruguay confirmaron públicamente el arresto de la señora Celiberti, sus dos hijos y el señor Universindo Rodríguez Díaz, alegando que ellos habían intentado cruzar la frontera entre Brasil y Uruguay, ingresando secretamente material subversivo. Durante cuatro meses se les mantuvo incomunicados, y, en el cuarto mes, a la señora Celiberti se le imputaron los cargos de 'asociación subversiva', 'violación de la Constitución por conspiración y actos preparatorios' y otras violaciones al Código Penal Militar en conjunción con el Código Penal Ordinario. Así, entonces, se ordenó que Lilian Celiberti fuera juzgada por un Tribunal Militar y que se le mantuviera en 'custodia preventiva'.

El Comité de Derechos Humanos observa, además, que el arresto y la detención inicial de Lilian Celiberti de Casariego tuvieron lugar presuntamente en territorio extranjero. El Comité no está limitado ni en virtud del artículo $1^{\circ}$ del Protocolo opcional 'individuos sujetos a jurisdicción', ni por el artículo 28 (1) de la convención 'individuos dentro del territorio y sujetos a jurisdicción'; por considerar estas alegaciones junto con la solicitud del secuestro subsecuente en territorio uruguayo, en la medida en que estos actos fueron perpetrados por agentes uruguayos actuando en suelo extranjero. 
El Comité de Derechos Humanos opina que la referencia que hace el artículo $1^{\circ}$ del Protocolo opcional a los 'individuos sujetos a su jurisdicción', no afecta la conclusión señalada anteriormente. Esto, porque en el citado artículo no se hace referencia al lugar donde la violación ocurrió sino que, más bien, alude al vínculo entre el individuo y el Estado en relación con la violación de cualquiera de los derechos establecidos en la convención, sin importar el lugar de su ocurrencia. El Comité de Derechos Humanos finalmente concluye:

El artículo 2(1) de la Convención impone como obligación a los Estados parte, la de respetar y asegurar los derechos "a todos los individuos dentro de su territorio y los que están sujetos a su jurisdicción"; pero ello no implica que el Estado parte en cuestión no pueda ser encontrado responsable bajo la Convención por las violaciones a los derechos que sus agentes cometan dentro del territorio de otro Estado, ya sea con el consentimiento del Gobierno de ese Estado o en oposición a ello (...) los Estados parte están obligados por el artículo 2, parágrafo 1, a respetar y asegurar los derechos de la Convención a todas las personas que puedan estar dentro de su territorio y a todas las personas sujetas a su jurisdicción. Esto significa que un Estado parte debe respetar y asegurar los derechos previstos en la Convención a cualquier persona dentro del poder o control efectivo de ese Estado parte. Este principio también se aplica a aquellos que se encuentren bajo el poder o control efectivo de las fuerzas de un Estado parte actuando fuera de su territorio, sin importar las circunstancias en las que ese poder o control efectivo fue obtenido, como aquellas fuerzas que constituyen un contingente nacional de un Estado parte a las que se les ha asignado una operación internacional de mantenimiento de la paz o de imposición de la paz. En consonancia con esto, sería inconcebible interpretar la responsabilidad mencionada en el artículo 2 de la convención como una manera de permitir que el Estado parte cometa violaciones a la Convención en el territorio de otro Estado, las cuales no podría cometer en su propio Estado (párr.10.3).

Desde 1981, el Comité de Derechos Humanos admitió la aplicación extraterritorial de la Convención, bajo las bases del requisito de autoridad o control efectivo en múltiples casos (Véase, NU, 1994, párr. 3; NU, 1998, párr.10; NU, 1998, párr.14; NU, 2001, párr.8; NU, 2004, párr. 6; NU, 2011, párr. 11). Adicionalmente, se estableció en la observación general 31 que: "el disfrute de los derechos de la Convención no está limitado a los ciudadanos de los Estados parte sino que también debe estar disponible para todos los 
individuos, sin importar su nacionalidad o apátrida (...)" (NU, 2010, pp.192-194).

Finalmente, debe concentrarse la atención en el análisis que la Corte Internacional de Justica (CIJ), realiza al alcance del PIDCP en su opinión consultiva sobre las consecuencias legales de la construcción de un muro en territorio palestino ocupado. En la mencionada opinión, la CIJ sostuvo que:

Mientras la jurisdicción de los Estados es principalmente territorial, puede que en algunos casos esta también se ejerza fuera del territorio nacional (...) así entonces y considerando el objeto y propósito del Pacto, pareciera natural que, incluso en aquellos casos, los Estados parte del Pacto deberían estar sujetos a cumplir con esas disposiciones (CIJ, 2004, párr. 109).

La CIJ falló en el mismo sentido cuando decidió el caso República Democrática del Congo vs. Uganda, al sostener que el DIDH se aplica en relación con los actos llevados a cabo por un Estado en el ejercicio de su jurisdicción fuera de su propio territorio (CIJ, República Democrática del Congo vs. Uganda, 2005, párr. 216).

\section{La Comisión y la Corte Interamericana de Derechos Humanos.}

La CoIDH ha elaborado la doctrina de control personal, en la cual sostiene que los individuos bajo 'autoridad y control' de un Estado, están a su vez sometidos a la jurisdicción de dicho Estado para efectos del DIDH. Lo anterior significa que ese organismo reclama la competencia ratione loci con respecto a los Estados, por los actos que ocurran en el territorio de otro Estado; cuando las presuntas víctimas estuviesen sujetas a autoridad y control de sus agentes (Véase, CoIDH, Salas, 1993, párr. 6; CoIDH, Callistus Bernard et al., 1994, párr. 6 y 8; CoIDH, Coard et al., 1999, párr. 37). Recientemente, en relación con las detenciones que se realizan en Estados Unidos, en la Bahía de Guantánamo, la Comisión encontró que "quien está bajo la autoridad y control de un Estado, sin importar sus circunstancias, no carece de protección legal en sus derechos humanos fundamentales o no derogables" (CoIDH, Detenciones en la Bahía de Guantánamo, 2002).

Es interesante que la $\mathrm{CoIDH}$ haya declarado recientemente admisible la petición interestatal formulada a raíz del caso Ecuador vs. Colombia (Aisalla, 2010), mediante la cual Ecuador argumenta 
que Colombia estaba en posición de control frente a los individuos que fueron asesinados en territorio ecuatoriano durante un ataque militar llevado a cabo en el suelo del país vecino, con el objetivo de destruir un campamento de las FARC (la llamada operación Fénix). En sus observaciones escritas a la petición interestatal, el Estado colombiano alega que la CoIDH no tiene la jurisdicción por ratione loci, debido al hecho de que las presuntas víctimas no estaban sujetas a la jurisdicción colombiana, como lo requiere el artículo $1^{\circ} .1$ de la Convención Americana (Observaciones del Estado de Colombia a la petición interestatal, 2009, pp. 5-20).

En ese sentido el Estado colombiano alegó que, como regla general, el concepto de 'jurisdicción' debe interpretarse desde una perspectiva territorial. Añade así que en la interpretación de los artículos $1^{\circ}$.1. y $2^{\circ}$ de la Convención Americana, la conclusión debe indicar que la ley se caracteriza por su aplicación territorial. "Consecuentemente, y en orden a que la protección sea efectiva, las personas que se beneficiarán de la mencionada protección deben estar localizadas dentro del territorio de dicho Estado" (Observaciones del Estado de Colombia a la petición interestatal, 2009 , pp. 6 y 10). De esta forma, el Estado colombiano advierte que debido a la dimensión territorial del término 'jurisdicción' señalado en el artículo $1^{\circ} .1$. de la Convención Americana, la muerte del señor Aisalla, nacional ecuatoriano, la cual tuvo lugar en Ecuador, no está sujeta a la jurisdicción del Estado colombiano (Observaciones del Estado de Colombia a la petición interestatal, 2009, p. 11).

El Estado colombiano sostiene que, de acuerdo con el derecho internacional, las únicas dos posibles excepciones a la regla que establece la jurisdicción territorial, se relacionan con operaciones militares o con los actos de diplomáticos o agentes consulares en el territorio de otros Estados. Ahora bien, de acuerdo a los pronunciamientos del Estado colombiano para considerar que un Estado ha ejercido su jurisdicción de manera extraterritorial por una operación militar exterior, debe demostrarse que existía ocupación militar o que el Estado que desplegó la operación militar tenía control sobre el territorio del otro Estado (Comunicación del Estado colombiano ante la CoIDH, 2010, párr. 30).

El Estado colombiano advierte que la llamada 'Operación Fénix', no equivalía ni a una ocupación militar ni a un control sobre el territorio. Lo anterior en el sentido de que no había una presencia 
permanente de las fuerzas militares colombianas en Ecuador. Además, resalta el Estado colombiano que sus fuerzas militares no buscaban destituir, reemplazar o sustituir al gobierno ecuatoriano o sus fuerzas militares. En conclusión, el Estado colombiano sostiene que en el presente caso los prerrequisitos necesarios para considerar que, como resultado de la 'Operación Fénix', Colombia ejerció jurisdicción extraterritorialmente sobre el territorio de Angostura (Ecuador) y las personas allí presentes, están ausentes (Comunicación del Estado colombiano ante la CoIDH, 2010, párr. 49).

La CoIDH inicia así su análisis desde el punto de vista del derecho internacional:

En el derecho internacional, las bases de la jurisdicción no son exclusivamente de carácter territorial, incluso pueden ser ejercidas en otras bases también. En este sentido, la CoIDH ha establecido que "bajo ciertas circunstancias, el ejercicio de su jurisdicción sobre los actos extraterritoriales no solo serán congruentes sino requeridos por las normas pertinentes" (CoIDH, Coard et al, 1999, párr. 37). Así, a pesar de que la jurisdicción se refiere usualmente a la autoridad sobre las personas que están dentro del territorio del Estado, los derechos humanos son inherentes a todos los seres humanos y no se basan en su nacionalidad o localización. En virtud del derecho interamericano de los derechos humanos, cada Estado Americano está obligado a respetar los derechos de todas las personas dentro de su territorio, como de aquellos presentes en el territorio de otro Estado, pero sujetos al control de sus agentes (CoIDH, Alejandre Jr. et al, 1999). Está posición coincide con la de otras organizaciones internacionales que, analizando la esfera de aplicación de los instrumentos de los derechos humanos internacionalmente reconocidos, han logrado evaluar su extraterritorialidad.

La CoIDH declaró la admisibilidad de la solicitud y analizó el fondo de la misma; sin embargo, en la decisión de admisibilidad define la pregunta esencial en esta materia cuando expresa:

Así, lo siguiente es esencial para la Comisión a efectos de determinar la jurisdicción: el ejercicio de autoridad sobre las personas por los agentes de un Estado, incluso si no están actuando dentro de su territorio, sin la necesidad de requerir la existencia de una formal, prolongada y estructurada relación legal en términos del tiempo puede elevar la responsabilidad de los Estados por los actos cometido por sus agentes en el exterior. Al momento de examinar el alcance de la jurisdicción de la Convención Americana, es necesario determinar si existe un nexo causal entre la conducta extraterritorial del Estado y la presunta violación de los derechos y libertades del individuo. 
Al respecto cabe resaltar, como se tratará más adelante, que en sus pronunciamientos la Corte Interamericana de Derechos Humanos (CIDH) no se ha ocupado en detalle de la cuestión atinente al alcance de la jurisdicción; sin embargo, ella sí ha manejado casos de violaciones trasnacionales de derechos humanos.

\section{Tribunal Europeo de Derechos Humanos.}

El TEDH en la decisión del caso Bankovic y otros vs. Bélgica y otros, insistió en que el término 'jurisdicción' que deriva del derecho internacional, es fundamentalmente -pero no de forma exclusiva-, territorial. El Tribunal aceptó que los actos de autoridades de 'Estados parte', cometidos fuera del territorio nacional o que pudieran producir efectos más allá del mismo podrían -en circunstancias excepcionales- recaer bajo la jurisdicción del 'Estado parte'. En el caso Bankovic, la aplicación fue sin embargo declarada inadmisible porque el ataque aéreo que tuvo lugar no se llevó a cabo para constituir un control efectivo sobre el área en cuestión.

El TEDH ya había concluido en una etapa más temprana, que el término 'jurisdicción' no se encuentra limitado al territorio nacional del Estado parte, pues por los actos de sus autoridades que produzcan efectos fuera del territorio el Estado puede incurrir en responsabilidad (Véase, TEDH, Drodz y Janousek vs. Francia y España 1992, párr. 91; CoEDH, República Federal de Alemana, 1965; CoEDH, Hess vs. Reino Unido 1975; CoEDH, Chipre vs. Turquía, 1975; CoEDH, X y Y vs. Suiza, 1977; CoEDH, W. vs. Reino Unido, 1983). El ejercicio de jurisdicción es, pues, una condición necesaria para que un Estado sea encontrado responsable por los actos $u$ omisiones imputables a él, cuando ellos produzcan una infracción a los derechos y libertades protegidas (TEDH, Ilascu y otros vs. Moldovia y Rusia, 2004, párr. 311).

En el caso Loizidou vs. Turquía, el Tribunal Europeo dictaminó que cuando un Estado ejerce control efectivo sobre un territorio, como es el caso de las ocupaciones militares, tiene jurisdicción (1995, párr. 62). Acerca de ello se expresó en los siguientes términos:

En este asunto el Tribunal recuerda que, si bien el artículo 1 establece límites en el alcance de la Convención, el concepto de "jurisdicción" bajo esta disposición no se limita al territorio nacional de las altas partes contratantes (...) la responsabilidad de las partes contratantes puede estar implicada por los actos de sus autoridades, sea que hayan actuado dentro o fuera de los límites nacionales, lo cual 
produce efectos fuera de su propio territorio (...) teniendo presente el objetivo y propósito de la Convención, la responsabilidad de una parte contratante también puede surgir cuando, como consecuencia de una acción militar -sea legal o ilegal- se esté ejerciendo un control efectivo sobre un área fuera del territorio nacional. La obligación de asegurar, en dicha área, los derechos y libertades establecidos en la Convención deriva del hecho de que tal control sea ejercido directamente, bien sea a través de sus fuerzas armadas o por medio de la administración local subordinada (Loizidou vs. Turquía, 1995, párr. 62). Esta decisión tomada por el TEDH, fue confirmada en el año 2001 en el caso Chipre vs. Turquía.

Las mencionadas circunstancias excepcionales que justifican una jurisdicción extraterritorial, también se aplican al artículo $5^{\circ}$ de la CEDH. Ya desde 1989, el Tribunal decidió en el caso Stocké vs. Alemania y dijo:

De acuerdo al artículo 1 de la Convención las Altas partes contratantes tienen que asegurar los derechos consagrados en el artículo 5 (1) a "todos los que estén dentro de su jurisdicción". Este compromiso no se limita al territorio nacional de la Alta parte contratante en cuestión, sino que se extiende a todas las personas que se encuentren bajo su actual autoridad y responsabilidad, ya sea que la autoridad sea ejercida dentro del propio territorio o en el exterior. Además (...) los agentes autorizados de un Estado no solo permanecen bajo su jurisdicción en el extranjero, sino que además traen cualquier otra persona "dentro de la jurisdicción" de dicho Estado al ejercer autoridad sobre esas personas. En la medida en que los actos u omisiones del Estados afecten a esas personas, la responsabilidad del Estado está comprometida (TEDH, Stocké vs. Alemania, 1989, párr. 166).

En casos más recientes, como el de Issa et al vs. Turquía, el TEDH expresó nuevamente que la responsabilidad de un Estado puede verse involucrada por la violación de los derechos y libertades de las personas que están en el territorio de otro Estado, al encontrarse bajo la autoridad y control de los agentes del primer Estado quienes estuvieran operando legal o ilegalmente en el territorio del segundo Estado. El test que aplica, entonces, es el de 'control efectivo'. De acuerdo al TEDH, la responsabilidad en este tipo de situaciones resulta del hecho de que el artículo $1^{\circ}$ de la Convención Europea no puede interpretarse de tal forma que permita a un Estado parte cometer violaciones a los derechos humanos en el territorio de otro Estado; violaciones que tampoco podría cometer en su propio territorio (TEDH, Issa et al vs. Turquía, 2004, párr. 71). 
En el mencionado caso Issa, el Estado demandado fue acusado de adelantar en la frontera, operaciones militares con el objetivo de perseguir y eliminar a presuntos terroristas. El TEDH aceptó en aquel entonces que, como consecuencia de esa acción, podría considerarse que el Estado demandado ha ejercido, temporalmente, el control global efectivo de una porción en particular del territorio en el cual estaba adelantando operaciones militares.

Finalmente, en relación con este asunto, me gustaría mencionar dos casos directamente relacionados con la práctica de entrega a la justicia: el primero, es el de Öcalan vs. Turquía (TEDH, 2005), quien era líder del Partido de los trabajadores de Kurdistán (PKK por sus siglas en inglés) secuestrado en Nairobi, Kenia, por el servicio secreto de Turquía. El TEDH decidió que Öcalan se encontraba dentro de la jurisdicción de Turquía desde el momento en que fue transferido físicamente de las instalaciones de la Policía en Kenia al control de los oficiales turcos en Nairobi. Por ello, dijo que es suficiente que la víctima haya sido físicamente entregada a la custodia y control de las autoridades turcas, por lo que no hay necesidad de solicitar evidencia de control sobre un lugar en particular.

El segundo caso, se refiere a la aprehensión de Al-Saadoon y Mufdhi en Irak. Ellos se encontraban detenidos en la 'Instalación Departamental de Detención Temporal', durante varios meses; primero, por miembros del ejército de los Estados Unidos y, luego, por militares del Reino Unido; con posterioridad fueron llevados a juicio ante un Tribunal de Irak. En la declaración de admisibilidad, el Tribunal afirmó que algunos de los detenidos que estuvieron en la prisión del Reino Unido, ubicada en territorio Iraquí, se encontraban a su vez dentro de la jurisdicción del Reino Unido puesto que estaban bajo el control total y exclusivo de facto y subsecuentemente de jure, ejercido por las autoridades inglesas en las instalaciones anteriormente señaladas (TEDH, Al-Saadoon y Mufdhi vs. Reino Unido, 2009). Así mismo, en su sentencia definitiva, el Tribunal es claro al señalar que:

Se ha aceptado que una Parte Contratante es responsable en virtud del artículo 1 de la Convención por todos los actos u omisiones de sus órganos, con independencia de que el acto u omisión en cuestión sea una consecuencia de la jurisdicción interna, o de la necesidad de cumplir con las obligaciones jurídicas internacionales. El artículo 1 no hace ninguna distinción en cuanto al tipo de norma o medida en cuestión y no excluye del escrutinio de la Convención ningún segmento de la "jurisdicción" de una Parte Contratante. Las fuerzas 
armadas del Estado demandado, después de haber entrado en Irak, tomaron medidas activas para llevar a los solicitantes dentro de la jurisdicción del Reino Unido, arrestándolos y manteniéndolos en centros de detención administrados por los británicos (Véase, TEDH, Al-Saadoon y Mufdhi vs. Reino Unido, 2009, párr. 128). En estas circunstancias, el Tribunal considera que el Estado demandado tenía la obligación primordial de garantizar que el arresto y la detención no terminaran de una manera que violara los derechos de los demandantes conforme a los artículos 2 y 3 de la Convención y en el artículo 1 del Protocolo n .13 (TEDH, Al-Saadoon y Mufdhi vs. Reino Unido, 2010).

Podemos concluir, entonces, que el Tribunal utiliza en principio una doctrina de control territorial pero, a su vez, acepta que en circunstancias excepcionales también aplica la extraterritorialidad. Sin embargo, sigue siendo difícil para el Tribunal de Justicia definir el alcance de los actos o de sus efectos necesarios para activar la jurisdicción, como en los casos de ocupación militar o de acciones antiterroristas ejecutadas extraterritorialmente; así como también las obligaciones positivas eventuales que surjan de dicha jurisdicción. En cambio, en el caso de la custodia y la detención, la situación es más clara, pues el Tribunal admite, de hecho, una doctrina de control de personal, mediante la cual el Estado tiene "la competencia para respetar (o violar) los derechos de un individuo que tiene en su custodia" (Satterthwaite, 2007, p. 1372).

\section{La detención por razones de seguridad bajo la lupa del Derecho Internacional de los Derechos Humanos}

El segundo tema que merece un mayor análisis, es la cuestión de si, y en qué medida, el DIDH acepta la categoría específica de la detención de seguridad, especialmente en el campo de la lucha contra el terrorismo. Como regla general se puede afirmar que el DIDH permite la detención de seguridad en un conjunto muy limitado de circunstancias e incluso, cuando se permite, ella está sujeta a muchas limitaciones que se aplican en todo momento, incluso en estados de emergencia y de guerra.

\section{El Pacto Internacional de los Derechos Civiles y Políticos y la detención por razones de seguridad.}

La detención por razones de seguridad no es, como tal, una violación del Pacto; sin embargo, hay criterios estrictos sobre los 
motivos y los procedimientos que han de aplicarse para su ejecución. Ya en 1982, el Comité de Derechos Humanos de la ONU escribió en su Observación General No 8 sobre el artículo $9^{\circ}$ del PIDCP, el cual se refiere al derecho a la libertad y a la seguridad de las personas, que el artículo $9^{\circ}(1)$ es aplicable a todas las formas de privación de libertad, ya sea en materia penal o en otros casos. En particular, la garantía fundamental consignada en el párrafo 4, es decir, el derecho a recurrir ante un tribunal para controlar la legalidad de la detención, se aplica a todas las personas privadas de su libertad en virtud de detención o prisión. Además, los Estados Parte tienen, de conformidad con el artículo $2^{\circ}(3)$, la obligación de asegurar que un recurso efectivo sea proporcionado en los casos en que el individuo afirme ser privado de su libertad con violación del Pacto. El Comité de Derechos Humanos de la ONU menciona explícitamente en el párrafo 4 de su comentario a la detención preventiva, lo siguiente:

(...) Si se utiliza la llamada prisión preventiva, por razones de seguridad pública esta debe ser controlada por las mismas disposiciones, es decir, no debe ser arbitraria, y debe basarse en los motivos y los procedimientos establecidos por la ley, la información de las razones se debe dar y el control judicial de la detención debe estar disponible, así como una indemnización en caso de incumplimiento (ONU, Comité de Derechos Humanos, 1994, párr(s).1, 2, 4 y 5).

Con todo, no queda claro cuál es el umbral de pruebas que debe ser aplicado para la detención de seguridad y si es el mismo para la detención de seguridad a corto, mediano o largo plazo. Además, es importante destacar que estas obligaciones se aplican también a las detenciones extraterritoriales de personas que se encuentran dentro de la custodia y el control efectivo del Estado; como lo señala el Comité de Derechos humanos:

Mientras el artículo 2 se expresa en términos de las obligaciones de los Estados Partes para con las personas como los titulares de derechos en virtud del Pacto, cada Estado parte tiene un interés jurídico en el cumplimiento que tengan los demás Estados Partes de sus obligaciones. Esto se deduce del hecho de que las "normas relativas a los derechos fundamentales de la persona humana" son obligaciones erga omnes (2004).

ElPacto impera, de igual forma, en situaciones de conflicto armado en las cuales las normas del derecho internacional humanitario (DIH) son aplicables. Es más, para interpretar determinados derechos 
consagrados en el Pacto son pertinentes normas más específicas del derecho internacional humanitario; ambas esferas del derecho, pues, son complementarias y no se excluyen mutuamente (ONU, Comité de Derechos Humanos, 2001, párr.3). El artículo $2^{\circ}$, en su párrafo 3 , requiere que en adición a una efectiva protección de los derechos del Pacto, los Estados Parte deben asegurar que los individuos tengan recursos accesibles y efectivos para reivindicar sus derechos. Ellos deben ser adaptados apropiadamente, de tal forma que se tome en cuenta la especial vulnerabilidad de ciertas categorías de personas, incluyendo en particular a los niños.

La falta de investigación y enjuiciamiento de los autores de tales infracciones podrían, de por sí, constituir una violación separada del Pacto. Estas obligaciones surgen principalmente en relación con aquellas conductas reconocidas como delitos en la legislación, ya sea nacional o internacional, como lo son la tortura y los tratos crueles, inhumanos y degradantes (artículo $7^{\circ}$ ), la ejecución sumaria y arbitraria (artículo $6^{\circ}$ ) y la desaparición forzada (artículos $7^{\circ}$ y $9^{\circ} \mathrm{y}$, con frecuencia, el $6^{\circ}$ ). Ninguna posición oficial justifica que aquellas personas que pueden ser acusadas de ser responsables por dichas violaciones, sean inmunes desde la perspectiva jurídica. Otros impedimentos para el establecimiento de la responsabilidad jurídica deben igualmente eliminarse, como ocurre con la defensa de la obediencia a órdenes superiores o los períodos excesivamente breves de prescripción en los casos en que tales limitaciones sean aplicables. También, los Estados Parte deben prestarse asistencia mutua para someter a la justicia a los sospechosos de haber cometido actos de violación del Pacto, punibles según el derecho nacional o internacional.

\section{La posición de la Comisión y la Corte Interamericana de Derechos Humanos.}

La jurisprudencia interamericana no declara que la detención por razones de seguridad, como tal, sea una violación de la Convención, en particular al artículo $7^{\circ}$ de la Convención Americana sobre Derechos Humanos $(\mathrm{CADH})$ en materia de la libertad personal. La detención por razones de seguridad es tratada como cualquier detención; de tal forma que será conforme a la $\mathrm{CADH}$ si no es arbitraria y se basa en motivos previamente establecidos por la ley. Esto incluye la garantía contra el arresto arbitrario y la detención mediante la estricta regulación de los fundamentos y los 
procedimientos de arresto y detención en virtud de la ley. Se incluye, además, la garantía de una supervisión judicial rápida y eficaz.

A efectos de evitar riesgos como los señalados, la Comisión sugiere que una demora de más de dos o tres días para llevar a un detenido ante una autoridad judicial en general no se considera razonable (CoIDH, Mckenzie et al [Jamaica], 2000). Sin embargo, ella reconoce que la privación de libertad de una persona también puede estar justificada en relación con la administración de la autoridad del Estado, más allá de la investigación y sanción de los crímenes donde las medidas de esta naturaleza son estrictamente necesarias. No obstante, ese organismo ha hecho hincapié en que cualquier tipo de detención debe, en todos los casos, cumplir con los requisitos de la legislación preexistente, nacional e internacional, incluida la exigencia de que la detención deba basarse en fundamentos y procedimientos claramente establecidos en la Constitución o en otras leyes demostrándose, así, que la detención es necesaria, justa y no arbitraria. La detención en tales circunstancias también debe ser objeto de control y de supervisión judicial y, cuando el Estado ha justificado la detención continua, debe serlo a intervalos razonables (Véase, CoIDH, Ferrer Mazorra et al [Estados Unidos], 2001; CoIDH, Reporte: El derecho a la vida y el terrorismo, 2002).

La Corte ha examinado estrictamente casos de detención basados en la ilegalidad y la arbitrariedad. En el caso Gangaram-Panday vs. Surinam (1994), llegó a la conclusión de que Surinam había violado la Convención por causa de la detención ilegal. Gangaram-Panday fue detenido por la policía militar en el aeropuerto de Paramaribo en Surinam, procedente de Ámsterdam, a raíz de un procedimiento de deportación. Fue retenido durante tres días en confinamiento militar, sin control judicial y se declaró que el privado de la libertad en forma ilegal se había suicidado. La CIDH concluyó, además, que, si bien el derecho a la libertad personal y la seguridad es irrevocable, el derecho a recurrir ante un Tribunal competente en virtud del artículo $7^{\circ}(6)$, que por su naturaleza es necesario para proteger los derechos no derogables durante la detención penal o administrativa, como el derecho a la integridad personal, no pueden ser objeto de derogación en el sistema interamericano. La Comisión Interamericana ha sostenido que hay otros componentes relacionados con el derecho a la libertad que no pueden ser negados, como lo serían el requisito de que los fundamentos y los procedimientos para la detención estén previstos por la ley o 
el derecho a ser informado de los motivos de la detención; igual sucede con ciertas garantías contra la incomunicación prolongada o la detención indefinida, incluyendo el acceso a un abogado, a la familia y la asistencia médica después de la detención.

\section{La detención por razones de seguridad y la jurisprudencia del Tribunal Europeo de Derechos Humanos (Sottiaux, 2008).}

El TEDH tiene una postura mucho más estricta cuando se trata de proteger el derecho a la libertad. Por ello, insiste continuamente en la importancia fundamental de las garantías contenidas en el artículo $5^{\circ}$ de su Convención, para asegurar el derecho de los individuos en una democracia a ser libres de detención arbitraria a manos de las autoridades. Por esa razón, el Tribunal aplica una prueba de legalidad y una de arbitrariedad. El Tribunal prohíbe la detención por razones de seguridad en virtud del artículo $5^{\circ}$ de la $\mathrm{CEDH}$, dado que ningún poder general de la prisión preventiva se puede encontrar en el artículo $5^{\circ}(1)$ (b) (TEDH, Lawless vs. Irlanda, 1960, párr. 14). Esto significa que el artículo $5^{\circ}$ (1) (c) no autoriza "una política de prevención general dirigida contra un individuo o una categoría de individuos que, como mafiosos, supongan un peligro a causa de su propensión a la delincuencia continua" (TEDH, Guzzardi vs. Italia, 1980, párr. 102).

Cabe señalar que el artículo $5^{\circ}(1)$ (c) solo puede ser utilizado en el contexto de la detención por razones de seguridad relacionadas con el enjuiciamiento de un delito. En ese caso, el derecho de hábeas corpus previsto en el artículo $5^{\circ}(4)$ se aplica, lo cual significa que es necesaria una pronta revisión por un tribunal independiente e imparcial establecido por la ley. Este recurso está disponible independientemente de la razón para la detención. Las garantías procesales y el alcance de la revisión, sin embargo, difieren según el tipo de libertad en juego. La expresión 'rápidamente' es más indulgente que 'sin demora', pero, según la jurisprudencia del Tribunal, es claro que debe existir un recurso mucho más efectivo dentro de una semana por lo menos (Véase, TEDH, Al-Nashif vs. Bulgaria, 2002; TEDH, Öcalan vs. Turquía, 2005; TEDH, Sahin vs. Turquía, 2005). Es más, en el caso Brogan, el Tribunal reconoció la relevancia de estas consideraciones en la persecución de delitos de terrorismo, pero aseveró que todas las detenciones no autorizadas judicialmente que excedan de cuatro días no cumplen con el criterio de la prontitud. 
En la actual jurisprudencia, el Tribunal rechaza de forma sistemática la incomunicación o la detención no reconocida con la total ausencia de aplicación de las garantías contenidas en el artículo $5^{\circ} \mathrm{y}$ las etiqueta como las violaciones más graves del derecho a la libertad y a la seguridad (Véase, TEDH, Kurt vs. Turquía, 1998; TEDH, Cakici vs. Turquía, 1999; TEDH, Luluyev y otros vs. Rusia, 2006).

\section{Normas internacionales de derechos humanos $y$ entregas extraordinarias.}

\section{El Pacto Internacional de los Derechos Civiles y Politicos y el Comité de Derechos Humanos.}

El Comité de Derechos Humanos ha dejado claro que el PIDCP, exige que los Estados Parte respeten y garanticen los derechos consagrados en el Pacto a todas las personas en su territorio y a todas las que se encuentren bajo su control, lo cual entraña la obligación de no extraditar, deportar, expulsar o retirar de otro modo a una persona de su territorio, cuando haya razones fundadas para creer que existe un riesgo real de daño irreparable, como el contemplado por los artículos $6^{\circ}$ (derecho a la vida) y $7^{\circ}$ (prohibición de la tortura o tratos o penas crueles inhumanos o degradantes) del Pacto, ya sea en el país al que se le va a trasladar o en cualquier otro al que la persona sea posteriormente conducida. Las autoridades judiciales y administrativas competentes deben ser conscientes de la necesidad de garantizar el cumplimiento de las obligaciones del Pacto de tales asuntos (Comité de derechos humanos, 1992, párr. 9; Comité de derechos humanos, 2004, párr. 12).

El Comité de derechos humanos de la ONU, precisó también en el caso Chinat $\mathrm{Ng}$ vs. Canadá que:

Si un Estado parte procede a extraditar a una persona dentro de su jurisdicción, en esas circunstancias (riesgo de pena de muerte) y si, como resultado de ello se crea un verdadero riesgo de que los derechos de la persona otorgados bajo la convención serán violados en otra jurisdicción, el Estado parte podría estar violando la Convención (1991, párr. 14.2).

\section{Corte Interamericana de Derechos Humanos.}

En el 2006, la Corte se pronunció sobre un caso histórico de secuestro transnacional y desaparición forzada en el que se enfrentó al tema de la responsabilidad conjunta del Estado. En efecto, en 
el asunto de Goiburú et al. vs. Paraguay (2006) la Corte tuvo que evaluar la práctica de la 'Operación Cóndor', una verdadera empresa criminal conjunta conformada para realizar los crímenes de secuestro, detención, tortura y desaparición forzada que contaba con oficiales militares y de inteligencia de Chile, Argentina, Bolivia, Paraguay y Uruguay, en la época de sus respectivas dictaduras militares. El objetivo de esa actividad criminal era luchar contra las actividades subversivas, mediante el intercambio de información, secuestro, detención preventiva, asesinatos selectivos y así sucesivamente. Desde luego, lo peligroso en relación con la demanda contra Paraguay fue la práctica sistemática de detenciones arbitrarias, torturas, ejecuciones extrajudiciales y desapariciones perpetradas por las fuerzas de inteligencia y de seguridad durante la dictadura de Alfredo Stroessner, bajo la 'Operación Cóndor'. En el párrafo 66, el Tribunal califica la responsabilidad del Estado de Paraguay como una clara situación de 'terrorismo de Estado', al comprobarse que el poder del ente gubernamental fue orquestado como medio y recurso para violar los derechos que deberían haber sido respetados y salvaguardados, lo que permitió que las acciones se llevaran a cabo mediante la colaboración interestatal (CIDH, Goiburú et al vs. Paraguay, 2006, párr. 66). En otras palabras, el Estado se convirtió en el principal factor de los graves crímenes cometidos.

Por otra parte, la Corte declaró que la prohibición de la desaparición forzada, perpetrada con la colaboración de autoridades de otros Estados del continente y la correspondiente obligación de investigar y sancionar, tienen carácter de jus cogens y, por tanto, son disposiciones inderogables del derecho internacional que establece un amplio alcance de las obligaciones internacionales erga omnes (CIDH, Goiburú et al vs. Paraguay, 2006, párr(s). 84 y 129). La Corte no solo se pronuncia sobre la vulneración de los derechos humanos y las libertades sino, también, en relación con las violaciones de los deberes positivos de investigar, enjuiciar y castigar, incluidas las obligaciones derivadas del derecho internacional en materia de extradición en casos de graves violaciones de derechos humanos. Allí, ese organismo hizo un nexo directo entre las obligaciones erga omnes y el deber positivo. El ejercicio pleno de la justicia impuesta a Paraguay fue la exigente obligación de haber solicitado la extradición del acusado con prontitud y con la debida diligencia; y se añadió que la inexistencia de tratados de extradición no constituye un motivo o justificación para no haber entablado una petición de este tipo (CIDH, Goiburú et al vs. Paraguay, 2006, párr. 130). 
En una opinión disidente, el Juez Antônio Cançado Trindade subrayó que los estados perpetraron crímenes de Estado en una escala transfronteriza o interestatal $\mathrm{y}$, al hacerlo, cometieron graves violaciones de derecho imperativo internacional (jus cogens) como peligrosas violaciones de derechos humanos. En este tipo de casos, tanto la responsabilidad internacional del Estado como la responsabilidad penal internacional del individuo (autor de las atrocidades) están en juego (Véase, Cançado, 2005, pp. 253-269). Es más, el Juez Cançado Trindade, hizo en su opinión disidente un paralelo entre los estados frente a las prácticas de secuestros y desapariciones forzadas en América Latina y en el programa internacional de entregas extraordinarias de los EE.UU.

\section{Tribunal Europeo de Derechos Humanos.}

Si bien el Tribunal tradicionalmente se niega a considerar la extradición o la deportación como parte de las obligaciones civiles o como una infracción penal con arreglo al artículo $6^{\circ}$ de la $\mathrm{CEDH}$, $\mathrm{y}$, por lo tanto, no admite la imparcialidad de los procedimientos de prueba (TEDH, Mamatkulov y Askarov vs. Turquía, 2005) ${ }^{5}$, en un par de casos se ocupa de la situación de elusión de extradición por secuestro y traslado con arreglo al artículo $5^{\circ}(1)$ de la CEDH. En efecto, ya en 1987, la Corte tuvo que lidiar con una entrega en relación con la extradición en el caso Bozano vs. Francia (1987).

Lorenzo Bozano, de nacionalidad italiana, fue condenado en ausencia. Las autoridades italianas le pidieron a Francia su extradición, pero ella fue denegada por resolución judicial, debido a la ausencia de aquél en la sentencia lo cual era considerado incompatible con el orden público francés. Posteriormente, el señor Bozano fue deportado por la policía francesa a Suiza, por una orden del ejecutivo francés (peligro para el orden público) y, luego, extraditado desde Suiza a Italia. El TEDH examinó la legalidad de la detención, lo que implica la ausencia de arbitrariedad. Los datos de que Bozano era incapaz de utilizar los recursos contra la orden de deportación y que no pudo contactar a su familia o a un abogado contribuyeron a la conclusión de la Corte: la privación de la libertad por parte de Francia no era ni legal, en el sentido del artículo $5^{\circ}(1)$, ni compatible con el derecho a la seguridad de la persona. Privar a Bozano de su libertad de esta manera significó, en realidad, una forma encubierta de extradición diseñada para eludir la decisión negativa sobre la solicitud de extradición (TEDH, Bozano vs. Francia, 1987, párr. 60). 
También, en el caso Iskandarov vs. Rusia, (2010) el Tribunal se enfrentó con el secuestro de Mukhamadruzi Iskandarov, después de una solicitud de extradición por las autoridades de Tayikistán que había sido desestimada por la Oficina del Fiscal General de Rusia. El secuestro en Moscú y su traslado a Tayikistán fueron cometidos por agentes rusos y tayikos. El Tribunal subrayó que la detención no solo debía ser legal (de conformidad con la legislación nacional), sino también compatible con la noción de no-arbitrariedad. La idea ha sido evaluada por el Tribunal sobre la base del análisis caso por caso, pero está claro que la mala fe, el engaño o la falta de autorización judicial durante mucho tiempo, sin fundamentos para hacerlo, son claramente arbitrarias para el TEDH. En el caso de Iskandarov, el Tribunal consideró que era lamentable que tales métodos oscuros fueran empleados por los agentes del Estado; además, advirtió que la privación de libertad se produjo en virtud de una sustracción ilegal diseñada para eludir el rechazo de la solicitud de extradición, por lo cual la detención no era necesaria en el curso ordinario de las medidas adoptadas con miras a la deportación o la extradición.

Incluso, el día dos de octubre de 2012, el Tribunal dictó sentencia en relación con un caso de extradición rusa en el cual se dio una situación de entrega extraordinaria: Abdulkhakov vs. Rusia; el asunto se refiere al secuestro en Moscú y al traslado a Tayikistán de un refugiado Uzbeko. Las autoridades judiciales rusas, incluido el Tribunal Supremo, accedieron a la solicitud de extradición por parte de Uzbekistán; la orden de extradición, sin embargo, no fue ejecutada como producto de la existencia de una medida cautelar prevista en el artículo 39 del Reglamento del Tribunal, como lo pudo señalar el TEDH. Varias semanas más tarde, el refugiado fue secuestrado y trasladado en secreto a Tayikistán, donde fue puesto bajo custodia con miras a su extradición a Uzbekistán. El Tribunal concluyó que el derecho de petición individual había sido violado, desde que la transferencia ilegal, en efecto, frustró el propósito de una medida cautelar impuesta inicialmente a Rusia para no transferirlo. Además, la Corte también encontró una violación al texto del artículo $3^{\circ}$ de la $\mathrm{CEDH}$, debido a la falta de evaluación por parte de Rusia del riesgo real de tortura al que se enfrentaría el solicitante, teniendo como antecedente que la transferencia llevada a cabo con anterioridad fue conducida en secreto y fuera de un marco legal que podría haber proporcionado las garantías necesarias (Buyse, 2012). El Tribunal incluso reiteró: 
Cualquier transferencia extrajudicial o entrega extraordinaria, por su elusión deliberada del debido proceso, es una negación absoluta del mandato de la ley y los valores protegidos por la Convención. Por lo tanto, equivale a una violación de los derechos más básicos garantizados por la Convención (TEDH, Abdulkhakov vs. Rusia, 2012, párr. 156).

El Tribunal no solo ha tratado casos de extradición y deportación desde el punto de vista del artículo $5^{\circ}$ (1) de la $\mathrm{CEDH}$, sino que también ha generado jurisprudencia interesante en materia de extradición y deportación en relación con el tenor literal del artículo $3^{\circ}$ de la CEDH. En muchos casos transnacionales, la detención por razones de seguridad va de la mano con el riesgo de violar el artículo $3^{\circ}$ de la CEDH. En el caso de Soering vs. el Reino Unido (1989), por ejemplo, se estableció el principio de que un Estado podría violar sus obligaciones en virtud de la $\mathrm{CEDH}$ si se extradita a un individuo a un Estado, en este caso los EE.UU., donde esa persona era propensa a sufrir tratos inhumanos o degradantes, o tortura. En tal caso, se presentaría una situación de flagrante denegación de justicia (Soering vs. Reino Unido, 1989, párr. 88). Obiter dicta: en ese asunto se extendió este principio para cubrir la posibilidad de una violación grave y flagrante de los derechos a un juicio justo conforme al artículo $6^{\circ}$ de la CEDH. Estos principios se unen a todos y cada uno de los signatarios de la CEDH y deben aplicarse a la extradición entre los firmantes de la Convención en la misma medida en que se apliquen a la extradición de un Estado parte a un tercer Estado.

La obligación de no devolución, no existiendo el deber de los Estados de devolver a una persona a otro Estado cuando haya un riesgo grave de que ella va a ser sometida a graves malos tratos, se ha extendido por el Tribunal a otras áreas tales como el derecho de los refugiados y la ley de migración. La autoridad más significativa que confirma la aplicación del principio de Soering a los casos de deportación es Chahal vs. Reino Unido. En ese caso, el TEDH descubrió que había pruebas suficientes de un riesgo real de sufrir malos tratos y subrayó que devolver a una persona en estas circunstancias sería una violación del artículo $3^{\circ}$, pues su aplicación es absoluta. No contiene, en consecuencia, excepciones dentro de ella ni puede ser derogada en tiempo de emergencia nacional, en virtud del artículo 15.

Así las cosas, en primer lugar, la propia jurisprudencia del Tribunal ha demostrado que, en la práctica, puede haber poca diferencia entre 
la extradición y otros traslados. En segundo lugar, en un contexto extraterritorial, es evidente que no tiene sentido hacer una distinción entre la tortura y los castigos inhumanos o degradantes, como, en este contexto, se requiere un ejercicio de prospectiva en el que no siempre es posible determinar si el tratamiento terminaría como uno u otro. En tercer lugar, en este tipo de casos no hay ninguna prueba de proporcionalidad, pues la única evaluación que tiene que hacerse es si el nivel mínimo de gravedad se ha cumplido a los efectos del artículo $3^{\circ}$; y ello, por supuesto, solo puede ser evaluado con independencia de las razones para el traslado o la extradición.

Muy recientemente, el TEDH ha ampliado su doctrina de devolución al artículo $6^{\circ}$, cuando dictó sentencia en el asunto de Othman (Abu Qatada) vs. Reino Unido, un caso relativo a la deportación de un sospechoso de terrorismo en el Reino Unido a Jordania; el demandante, Omar Othman, había huido de Jordania al Reino Unido en 1993. Allí pidió asilo, alegando que había sido detenido y torturado por las autoridades jordanas; en 1994 empezó a ser reconocido como refugiado y se le concedió permiso temporal para permanecer en el Reino Unido y, en 1998, solicitó quedarse por tiempo indefinido allí. En el 2002, mientras que su aplicación aún estaba en estudio, fue arrestado y llevado a prisión bajo la Ley sobre Antiterrorismo, Delincuencia y Seguridad de 2001. En el 2005, se le notificó un aviso de intención de deportarlo. Él cuestionó su posible deportación, alegando que existía un riesgo real de que sería sometido a tortura a su regreso a Jordania, todo ello con la violación del artículo $3^{\circ}$ de la CEDH. También, temía que iba a enfrentar un nuevo juicio por delitos de terrorismo por los cuales había sido condenado en ausencia en 1999.

Otham, afirmó, entre otras cosas, que existía un riesgo real de que las pruebas obtenidas mediante tortura -de él o, bien, de otros acusados $u$ otros presos- serían admitidas en su contra durante el nuevo juicio, con violación del artículo $6^{\circ}$ de la CEDH (Smet, 2012). Por ello, el TEDH dictaminó que ese texto legal se violaba si el solicitante era deportado a Jordania, porque existía un riesgo real de que las pruebas obtenidas mediante tortura de los otros acusados serían usadas en su contra durante su nuevo juicio. Debido a que la admisión de la prueba podría hacer todo el proceso no solo inmoral e ilegal, sino también sembrar profundas dudas sobre sus resultados, el Tribunal sostuvo que constituiría una flagrante denegación de justicia. A tal efecto, utilizó un lenguaje claro y llamativo para 
destacar sus hallazgos en el caso Othman; el siguiente pasaje de la sentencia merece ser citado en su totalidad:

Ningún sistema legal basado en el mandato de la ley puede tolerar la admisión de pruebas -no obstante confiables- que han sido obtenidas por esta práctica bárbara como la tortura. El proceso de prueba es una piedra angular del mandato de la ley. La prueba obtenida a través de la tortura daña irreparablemente ese proceso; esto sustituye a la fuerza de la supremacía de la ley y contamina la reputación de cualquier Tribunal que la admita. La prueba obtenida a través de tortura es excluida para proteger la integridad del proceso judicial y, en última instancia, el propio Estado de Derecho (TEDH, Othman (Abu Qatada) vs. Reino Unido, 2012, párr. 264).

Como la Corte señala, esta es la primera vez que se dictamina que la expulsión violaría el texto del artículo $6^{\circ}$, al subrayar que la "flagrante denegación de justicia" es una prueba rigurosa de injusticia. Esta expresión está presumiblemente contenida en la sentencia con el objetivo de aliviar cualquier preocupación que el Reino Unido o cualquier otro Estado miembro pueda tener sobre el alcance de la sentencia, así como para contrarrestar cualquier crítica que el Tribunal pudiera enfrentar como consecuencia de su entrega. En otras palabras, no se excluye la posibilidad de que consideraciones similares puedan aplicarse con respecto a las pruebas obtenidas por otras formas de malos tratos que se encuentran a la altura de la tortura. La flagrante denegación de justicia de la prueba tiene un alto umbral, pero es aplicable a las situaciones transnacionales que impidan a los valores fundamentales de la CEDH permanecer protegidos en situaciones de detención secreta.

En su más reciente sentencia del trece de diciembre de 2012, en el caso de El-Masri vs. la ex República Yugoslava de Macedonia, la Gran Sala ha dado su primer fallo sobre el régimen de entrega extraordinaria. El demandante había reclamado violaciones tanto a los textos de los artículos $3^{\circ}$ y $5^{\circ}$ (secuestro, tortura y detención; incomunicación, traslado y detención secreta en Afganistán, ocultamiento de una entrega positiva a Albania) como al artículo 13 (tutela judicial efectiva) y, además, la falta de una efectiva investigación judicial relacionada con la obligación positiva de proteger. El Tribunal se encontraba, entonces, en realidad frente a un secuestro organizado transnacional y a la desaparición forzada de una operación coordinada de las autoridades de Macedonia, EE.UU., Afganistán (y tal vez Alemania), lo cual se evalúa en el marco del Convenio a la luz de las obligaciones de Macedonia. 
Fue, justamente, en la Comisión de Venecia del Consejo de Europa en la que se subrayó la obligación de los Estados de tomar medidas eficaces para proteger a los individuos contra el riesgo de desaparición, así como de llevar a cabo una pronta investigación efectiva frente a las demandas de personas detenidas y que no han sido vistas desde entonces. Aunque la Comisión de Venecia en su dictamen llegó a la conclusión de que la CEDH no garantiza el derecho a no ser extraditado o deportado, hace hincapié en que, de acuerdo con la doctrina Soering, un Estado puede ser responsable de una violación de los contenidos de los artículos $2^{\circ}$ y $3^{\circ}$, también en casos flagrantes de posible violación de los textos de los artículos $5^{\circ}$ y $6^{\circ}$ de la CEDH. Esto, cuando su decisión, autorización u otras acciones, han creado un riesgo real de violación de tales derechos por parte del Estado al que se transfiere el prisionero. Ello carece de relevancia si el Estado en cuyo territorio la violación tendrá o en última instancia tendría lugar se encuentra también obligado por la CEDH. La Comisión de Venecia llegó a la conclusión de que los Estados miembros del Consejo de Europa (2006) han infringido varias obligaciones jurídicas internacionales al violar los derechos humanos, incluido el artículo $5^{\circ} \mathrm{y}$ al no respetar su deber de proteger y garantizar (vale decir, los deberes de investigar, procesar y juzgar).

Así, el TEDH falla por unanimidad que Macedonia ha violado el texto del artículo $3^{\circ}$ (tortura), tanto desde una perspectiva procesal como sustancial; es más, la detención, el secuestro y traslado de El-Masri es también una violación "particularmente grave" de los contenidos de los artículos $5^{\circ}, 8^{\circ}$ y 13 de la CEDH.

Desde luego, fue gracias a esa decisión que, por primera vez, ElMasri obtuvo justicia, pues sus actuaciones en Macedonia no fueron tomadas en serio, sus acciones judiciales en los EE.UU. fueron bloqueadas por falta de jurisdicción por razones de privilegio de secreto de Estado y, añádase, su demanda ante la Comisión Interamericana de Derechos Humanos se encuentra pendiente desde el 2008.

\section{Conclusión}

\section{El secuestro y la detención por razones de seguridad: obligaciones negativas y positivas.}

El análisis de la jurisprudencia internacional en materia de derechos humanos acabado de hacer, demuestra claramente que la 
detención por razones de seguridad relacionada con medidas administrativas especiales y que se ejecute desviándose de los procedimientos de extradición ordinaria, no pertenece al reino libre de la rama ejecutiva del gobierno. La seguridad por razones de detención debe ser legal y utilizada de tal forma que no dé lugar a la arbitrariedad o el abuso de poder; además, debe ser sometida a una pronta y eficaz revisión judicial (hábeas corpus).

La entrega extraordinaria es también una medida administrativa especial, pero una que fundamentalmente cambia el significado de la entrega, pues el objetivo no es (más) juzgar a una persona, sino mantenerla en detención secreta durante los interrogatorios. Los estados que participen en entregas extraordinarias tienen que aplicar las disposiciones del DIDH, incluidos los de detención por razones de seguridad. Por esta razón, las sentencias del TEDH en los casos El Masri vs. Macedonia y Al Nashiri vs. Polonia son de suma importancia, porque se trata de pronunciamientos claves que contienen los estándares a seguir en estos casos.

Un claro ejemplo de la línea que maneja el TEDH se refleja en los pronunciamientos del 24 de Julio 2014, con los cuales el Tribunal condena en dos casos a Polonia por permitir en su territorio interrogatorios y retenciones secretas por parte de la CIA (TEDH, Nashiri vs. Polonia, 2014); también hizo lo mismo en el caso de Husayn (Abu Zubaydah) vs. Poland (TEDH, 2014). Los demandantes, un palestino y un saudí -capturados en Pakistán y Dubai, respectivamente-, permanecen hasta hoy encarcelados en la bahía de Guantánamo. La Corte considera que Polonia colaboró en alguno de los vuelos secretos y facilitó a la CIA apoyo logístico para ejecutar las reclusiones en prisiones secretas y los traslados aéreos, que se consideran vulneraciones de los derechos humanos.

La Corte concluye, por unanimidad, que con su cooperación en la detención y facilitación del interrogatorio, Polonia violó cinco de los derechos fundamentales de Al Nashiri y Husayn -a la libertad y a la seguridad, al respeto a la vida privada y familiar, a tener un recurso efectivo y a un proceso justo-, además de vulnerar la Convención que prohíbe las torturas y el trato degradante. Los jueces destacaron también que el gobierno polaco no ha cumplido con su obligación de facilitar el procedimiento judicial y que no ha enviado los elementos de prueba solicitados por el Tribunal. 


\section{Entrega extraordinaria: la inexistencia de carta blanca para el poder ejecutivo y la necesidad de la supervisión judicial.}

Los tribunales nacionales deben ser competentes tanto para realizar búsquedas en orden a combatir los casos de arbitrariedad o de abuso de poder como para analizar la aplicación de los instrumentos de cooperación, por ejemplo, las MLA o las medidas administrativas especiales. Lo anterior, en razón al impacto que puedan generar los casos de entregas extraordinarias en los derechos de los ciudadanos, incluidas las graves violaciones a los derechos humanos y la comisión de actos ilícitos como delitos. Ya es tiempo de dejar de lado doctrinas como la del acto de Estado, Actes du gouvernment, o privilegios (inmunidad del interés público-secreto de estado) para que, en lugar de ello, se imponga la supervisión judicial. Daré solo dos ejemplos que nos guían en esa dirección.

El primero, es un fallo de la Corte Suprema de Australia en el caso Moti vs. La Reina (2011). Moti, de nacionalidad australiana, fue expulsado de las Islas Salomón en el 2007 y acusado en virtud de la legislación australiana por la comisión de delitos sexuales sobre menores, que tienen alcance extraterritorial. En los procedimientos que fueron apelados durante todo el camino hasta la Corte Suprema de Australia, Moti sostuvo que su deportación fue una extradición encubierta y una expulsión ilegal, lo que para él se tradujo en una persecución con abuso del proceso.

El Commonwealth, con respecto al caso mencionado, argumentó que la Corte Suprema se encontraba impedida, en virtud de la doctrina del acto de Estado, para considerar si fue o no ilegal el traslado de Moti a las Islas Salomón. Sin embargo, en una sentencia que contó con una mayoría de seis magistrados y la oposición de uno, la Corte concluyó que la decisión de un funcionario extranjero puede ponerse en duda al impedir a los tribunales considerar el asunto.

Determinada la doctrina del acto de Estado, esto no impidió decidir si la deportación ilegal había ocurrido o no; luego, la Corte volvió a analizar si la deportación ilegal representó la persecución de un abuso de proceso. Ese organismo judicial observó que Moti solo estaba disponible en Queensland para la acusación y el juicio, como consecuencia de su expulsión ilegal de las Islas Salomón; por lo tanto, la determinación de si un abuso del proceso se había producido requiere determinar, necesariamente, si la deportación de Moti fue ilegal y por qué lo fue. Adicionalmente, la Corte también 
sostuvo que, con fundamento en el interés público, un Tribunal de justicia debe garantizar que sus procesos sean manejados de manera justa por el Estado y el ciudadano, porque, de no hacerlo, erosionará la confianza pública, la cual es depositada constitucionalmente en los Tribunales para proteger la integridad y la imparcialidad de sus procesos. Finalmente, y luego de un largo análisis, la Corte llegó a la conclusión de que la persecución fue un abuso del proceso.

El segundo ejemplo, es un fallo emitido por la Corte canadiense de Apelaciones en el caso Estados Unidos vs. Khadr (2011) en el cual la apelación plantea cuestiones fundamentales relativas a la apropiada respuesta judicial frente a la violación de los derechos humanos de una persona, cuya extradición se solicita por cargos de terrorismo. En el mencionado caso, Estados Unidos le pagó a la agencia de inteligencia paquistaní ISI medio millón de dólares para secuestrar a Abdullah Khadr en Islamabad, Pakistán, en el 2004. Khadr, un ciudadano canadiense, era sospechoso de suministrar armas a las fuerzas de Al Qaeda en Pakistán y Afganistán. Después de su secuestro, Khadr fue detenido en secreto bajo custodia durante catorce meses y sometido a interrogatorios y golpes hasta que se logró su cooperación con el ISI con fines de inteligencia. El ISI se negó a tratar con el gobierno canadiense pero sí tuvo contacto con un oficial del CSIS. Las autoridades estadounidenses rechazaron la solicitud del oficial del CSIS para que Khadr tuviera acceso consular y el ISI le negó el acceso durante tres meses, además se resistieron a llevarlo ante los tribunales paquistaníes; es más, después de que el ISI había utilizado a Khadr como fuente de inteligencia antiterrorista, este organismo estaba dispuesto a ponerlo en libertad. No obstante, los norteamericanos insistieron en que el ISI mantuviera a Khadr en detención secreta durante otros seis meses para permitir a los Estados Unidos llevar a cabo una investigación criminal e iniciar el proceso de posible entrega de Khadr a los Estados Unidos de América.

Cuando Khadr fue, finalmente, repatriado a Canadá, Estados Unidos trató de tenerlo extraditado por cargos de terrorismo; el juez concedió la suspensión del procedimiento sobre la base de que al permitir que los procedimientos continuaran en vista de la mala conducta del Estado solicitante constituiría un abuso del proceso judicial, el juez de extradición estableció la existencia de una mala conducta estatal la cual compromete la imparcialidad de la audiencia y socava la integridad del proceso judicial. Por ello, el juez de extradición señala en su pronunciamiento que una suspensión solo debe ser concedida en el más claro de los casos, como el de Khadr: 
En las democracias civilizadas, el mandato de la ley debe prevalecer sobre los objetivos de inteligencia. En este caso, la suma de violaciones de derechos humanos sufridas por Khadr son a la vez impactantes e injustificables. Aunque Khadr podría haber poseído información de valor de inteligencia, él sigue teniendo derecho a las garantías y a los beneficios de ley, en contraposición a la detención arbitraria e ilegal en un centro de detención secreto donde fue sometido a maltratos físicos. Estados Unidos fue la fuerza impulsora detrás de la detención de Khadr por catorce meses en Pakistán, al pagar una recompensa de 500.000 dólares por su captura. La agencia de inteligencia de Estados Unidos actuó de manera concertada con el ISI al demorar el acceso consular por DFAIT a Khadr durante tres meses, en contra de las disposiciones de la Convención de Viena. Estados Unidos, en contra de los deseos de Canadá, presionó al ISI para retrasar la repatriación de Khadr a causa de la insatisfacción que les causaba que Khadr fuera liberado sin cargos, a pesar de que no había pruebas admisibles en las cuales se pudieran basar los cargos en ese momento. En mi opinión, dada esta falta grave, no puede haber un caso más claro que merezca una suspensión (Canadá, Corte de Apelaciones, Estados Unidos vs. Khadr, 2011, párr. 150).

\section{Dimensión transnacional de las obligaciones internacionales, positivas y negativas, de derechos humanos.}

El programa de entregas extraordinarias es defacto, de desaparición forzada transnacional; sin embargo, las obligaciones de derechos humanos europeas son, a pesar de tener carácter universal y algunas de ellas valor de jus cogens y erga omnes, aplicables dentro de la jurisdicción de un Estado parte en los convenios internacionales de derechos humanos. Dentro de las organizaciones políticas regionales, como la Unión Europea, las normas transnacionales se ponen en marcha. Un buen ejemplo es el artículo 19 (2) de la Carta Europea de Derechos Fundamentales: “Nadie podrá ser devuelto, expulsado o extraditado a un Estado en el que corra un grave riesgo de que él o ella pueda ser sometido a la pena de muerte, a tortura o a otros tratos inhumanos o degradantes" (Unión Europea, 2000).

Además, tanto las obligaciones internacionales positivas de derechos humanos como el contenido de la obligación de investigar, procesar y juzgar las graves violaciones del DIDH, en tratándose de delitos graves, son todavía poco desarrolladas en relación con la cooperación transnacional en materia penal. Si bien la Organización de las Naciones Unidas adoptó en el 2006 la Convención Internacional para la Protección de todas las Personas 
contra las Desapariciones Forzadas, en la misma no se reflejan las obligaciones específicas relacionadas con la cooperación internacional en materia penal (Vermeulen, 2012). Un primer paso, aunque tímido, se puede encontrar en la jurisprudencia de la $\mathrm{CIDH}$, que califica la obligación de cooperar en el traslado de los perpetradores ante la justicia como una obligación erga omnes (CIDH, La Cantuta vs. Perú, 2006, párr. 160).

Es más, a la luz de la jurisprudencia del DIDH es sorprendente ver cuán difícil ha sido abrir investigaciones judiciales en los países europeos con respecto a la práctica de las entregas extraordinarias y que ha sido aún más difícil reunir las pruebas debido a la falta de cooperación de las autoridades ejecutivas y a las limitaciones transfronterizas (Nino, 2008). De igual forma, sorprende que en Estados Unidos no se hayan abierto investigaciones judiciales penales en lo absoluto, teniendo en cuenta que el gobierno tiene el deber de investigar las entregas extraordinarias (Center for Human Rights and Global Justice, 2004, p. 8).

Incluso, dado que existe una falta evidente de mecanismos de aplicación internacional, ya es hora de generar, tanto en la legislación como en el DIDH, disposiciones más específicas sobre la obligación positiva en relación con la cooperación en materia penal. Obstáculos graves tales como la inmunidad del interés público, el secreto de Estado o inmunidades personales, deben ser eliminados; locus standi, bajo los procedimientos internos que deben ser garantizados. También, es sorprendente ver cuántos obstáculos se pueden generar en los EE.UU. bajo el Alien Tort Statute, la ley de protección de víctimas de tortura y así sucesivamente, lo que lleva a la falta de rendición de cuentas por las violaciones realizadas a las normas internacionales establecidas en materia de derechos humanos.

Las autoridades estatales deben estar obligadas a utilizar los instrumentos de asistencia legal mutua (MLA) de manera eficaz, y no dejarlos a un lado por consideraciones políticas, como ocurrió con las solicitudes de asistencia judicial MLA en Italia y Alemania, en relación con las investigaciones judiciales sobre entrega extraordinaria. Las relaciones diplomáticas no deben prevalecer cuando se trata de las más graves violaciones de derechos humanos y de la dignidad humana; de lo contrario, estas se enfrentarían a un velo de impunidad y de flagrante negación de la justicia. 


\section{Notas}

1 Está catalogado como un documento clasificado.

2 Está catalogado como un documento clasificado.

3 Declaración en Panel One, segundo día de la audiencia pública de la Comisión Nacional sobre Ataques Terroristas contra Estados Unidos.

4 Para el análisis de la sentencia, ver páginas 20 y siguientes bajo el capítulo Normas Internacionales de derechos humanos y entregas extraordinarias, y la conclusión final.

5 En el contexto de las denuncias acerca de la imparcialidad de los procedimientos de extradición de Turquía, el Tribunal Europeo ha reiterado, en el párrafo 82 , que "las decisiones relativas a la entrada, estancia y expulsión de extranjeros no se refieren a la determinación de derechos $\mathrm{u}$ obligaciones de carácter civil de un solicitante o de un cargo criminal en su contra, en el sentido del inciso 1 artículo $6^{\circ}$ de la Convención".

\section{Referencias}

Al Nashiri vs. Polonia. (2014, julio 24). Sentencia $n^{\circ}$ 28761/11. Tribunal Europeo de Derechos Humanos.

Al-Saadoon and Mufdhi vs. Reino Unido. (2009, junio 30). Decisión de admisibilidad. Tribunal Europeo de Derechos Humanos.

Asamblea del Consejo Europeo. (2007). Background information on the work of the Parliamentary Assembly of the Council of Europe. Recuperado de http:/ / www.assembly.coe.int/CommitteeDocs/2007/ENMarty_09072007. htm.

Bozano vs. Francia. (1987, diciembre 2). Tribunal Europeo de Derechos Humanos.

Buyse, A. (2012). Extraordinary rendition, forced labour and evidence obtained by torture. Recuperado de http://ukhumanrightsblog.com/2012/10/16/ extraordinary-rendition-forced-labour-and-evidence-obtained-bytorture-antoine-buyse/Ferrer Mazorra et al. (Estados Unidos). (2001, 4 de abril). Comisión Interamericana de Derechos Humanos.

Cakici vs. Turquía. (1999, julio 8). Tribunal Europeo de Derechos Humanos.

Cameron, D. (1998). Abducting Terrorist Overseas for Trial in the United States: Issues of International and Domestic Law. Texas International Law Journal, 23(1), 1-54. 
Cançado Trindade, A. (2005). Complementarity between State Responsibility and Individual Responsibility for Grave Violations of Human Rights: The Crime of State Revisited. En M. Ragazzi, (ed.), International Responsibility Today - Essays in Memory of O. Schachter. Leiden: Martinus Nijhoff Editores.

Center for Human rights and global justice. (2004). Torture by Proxy: International and Domestic Law applicable to "extraordinary renditions". New York.

Bassiouni C. M. (2007). International Extradition: United States Law E Practice. New York: Oxford University Press.

Chipre vs. Turquía. (2001, mayo 10). Sentencia. Tribunal Europeo de Derechos Humanos.

Comisión Interamericana de Derechos Humanos. (1993). Reporte n . 31/93 Caso 10.573, Salas (Estados Unidos).

Comisión Interamericana de Derechos Humanos. (1994). Reporte nº 14/94, Petición 10.951, Callistus Bernard et al. (Estados Unidos).

Comisión Interamericana de Derechos Humanos. (1999). Reporte $\mathrm{N}^{\circ}$. 109/99, Caso 10.951, Coard et al. (Estados Unidos).

Comisión Interamericana de Derechos Humanos. (1999). Reporte №. 86/99, Caso 11.589, Armando Alejandre Jr. et al. (Cuba).

Comisión Interamericana de Derechos Humanos. (2009). Observaciones del Estado Colombiano a la petición interestatal PI-2.

Comisión Interamericana de Derechos Humanos. (2010). Comunicación del Estado Colombiano. No. 31461/1312.

Comisión Interamericana de Derechos Humanos. (2012). Decision on Request for Precautionary Measures (Detainees at Guantánamo Bay, Cuba).

Comisión Interamericana de Derechos Humanos. (s.f.). The Right to Life and Terrorism. Recuperado de www.cidh.oas.org/Terrorism/Eng/ part.d.htm; ver también: Comité de Asuntos Internacionales. (2007). Extraordinary rendition in U.S. counterterrorism policy: the impact on transatlantic relations. Washington: U.S. Government printing office. Recuperado de foreignaffairs.house.gov/110/34712.pdf.

Comité de Derechos Humanos. (1991). Chitat Ng vs. Canada, UN Doc: CCPR/C/49/D/469/1991.

Comité de Derechos Humanos. (1994). Compilación de Comentarios y Recomendaciones Generales adoptados por las Organizaciones de Derechos Humanos. UN. Doc. HRI/GEN/1/Rev.1. 
Comité de Derechos Humanos. (1994). Observaciones finales sobre Chipre. (Doc. UN CCPR/C/79/Add.39).

Comité de Derechos Humanos. (1998). Observaciones finales sobre Israel. (Doc. UN CCPR/C/79/Add.93). Comité de Derechos Humanos. (1998). Final Observations on Belgium (Doc. UN. CCPR/C/79/Add.99).

Comité de Derechos Humanos. (2001). Observaciones finales sobre los Países Bajos. (Doc. UN CCPR/CO/72/NET9).

Comité de Derechos Humanos. (2001). Comentario General n 29 en Estados de emergencia. Anexo VI.

Comité de Derechos Humanos. (2004). Observaciones finales sobre Belgica. (Doc. UN CCPR/CO/81/BEL).

Consejo de Europa, Asamblea Parlamentaria. (2006). The Fava inquiry of the European Parliament. Recuperado de www.europarl.europa.eu.

Consejo Europeo de Derechos Humanos, Secretaría general. (2006). Reporte por el Secretario General en el uso de sus poderes en virtud del artículo 52 de la Convención Europea de Derechos Humanos. Recuperado de https://wcd. coe.int $/$ ViewDoc.jsp?id=976731\&Site=COE.

Consejo de Europa, Asamblea Parlamentaria. (s.f.). The Dick Marty Report of the Council of Europe. Recuperado de assembly.coe.int / main.asp.

Consejo de Europa, Asamblea Parlamentaria. (2007). Secret detentions and illegal transfers of detainees involving Council of Europe member states: second report. Recuperado de assembly.coe.int

Consejo Europeo, Comisión de Venecia. (2006). Opinion on the international legal obligations of council of europe member states in respect of secret detention facilities and inter-state transport of prisoners. Recuperado de http:/ / www. venice.coe.int/webforms/documents/?pdf=CDL-AD(2006)009-e.

Corte Internacional de Justicia. (2004). Advisory Opinion of the International Court of Justice on the Legal Consequences of the Construction of a Wall in the Occupied Palestinian Territory. Recuperado de http://www.icj-cij.org/ homepage/sp/advisory/advisory_2004-07-09.pdf.

Corte Internacional de Justicia. (2005). Reports of judgments: Case concerning Armed Activities on the Territory of the Congo (Democratic Republic of Congo vs. Uganda). Recuperado de http://www.icj-cij.org/docket/ files/116/10455.pdf.

Drozd y Janousek vs. Francia y España (1992, junio 26). Sentencia. Tribunal Europeo de Derechos Humanos. 
Ecuador vs. Colombia. (2010). Petición Interestatal de admisibilidad PI-2. Comisión Interamericana de Derechos Humanos.

Estados Unidos vs. Noriega y otros. (1990, junio 8).Tribunal de Distrito de los Estados Unidos, Distrito Sur de Florida.

Estados Unidos vs. Alvarez-Machain. (1992, junio 15). 504 U.S. 655. Corte Suprema De Justicia de los Estados.

Estados Unidos de América vs. Khadr. (2011, junio 5). Tribunal Militar de Guantánamo.

Estados Unidos. Senado, Comité de Inteligencia, Informe Feinstein. (2014). Comité de estudio del programa de detenciones e interrogatorios de la CIA.Recuperadodehttp:/ /ep00.epimg.net/descargables/2014/12/09/ cce7a160cfbeeb86dcd1087d818d6b6c.pdf; otra fuente: http://www. nytimes.com/interactive/2014/12/09/world / cia-torture-reportdocument.html?_r=0.

Frisbie vs. Collins. (1952, marzo 10). 342 U.S. 519. Corte Suprema De Justicia de los Estados Unidos.

Gangaram Panday vs. Surinam. (1994, enero 21). Corte Interamericana de Derechos Humanos.

Geiss, R. \& Petrig, A. (2011). Piracy and Armed Robbery at Sea - The Legal Framework for Counter-Piracy Operations in Somalia and the Gulf of Aden. Oxford: Oxford University Press.

Goiburú y otros vs. Paraguay. (2006, septiembre 22). Corte Interamericana de Derechos Humanos.

Guzzardi vs. Italia. (1980, 6 de noviembre). Tribunal Europeo de Derechos Humanos.

Hirsch, M. (2012). Anticipative criminal investigation, Theory and Counterterrorism Practice in the Netherlands and the United States. La Haya: TMC Asser Press.

Human Rights Watch (2005). Black Hole: The Fate of Islamist rendered to Egypt.

Husayn (Abu Zubaydah) vs. Polonia. (2014, julio 24). Sentencia $N^{\circ} 7511 / 13$. Tribunal Europeo de Derechos Humanos.

Ilascu y otros vs. Moldovia y Rusia. (2004, julio 8). Sentencia. Tribunal Europeo de Derechos Humanos.

Illuminati, G. (2010). Nuovi Profili del segreto di stato e dell'attività di inteligencia. Torino: G. Giappichelli Editore. 
Iskandarov vs. Rusia. (2010, 23 de septiembre). Tribunal Europeo de Derechos Humanos.

Issa et al. vs. Turquía. (2004, noviembre 16). Sentencia. Tribunal Europeo de Derechos Humanos.

Johnson, R. (2009). Extraordinary rendition: a wrong without a right? Richmond Law Review, 43(3), 1135-1174.

Ker vs. Illinois. (1886, Diciembre 10). 119 U.S. 436. Corte Suprema De Justicia de los Estados. Unidos.

Kurt vs. Turquía. (1998, mayo 25). Tribunal Europeo de Derechos Humanos.

La Cantuta vs. Perú (2006, noviembre 29). Corte Interamericana de Derechos Humanos.

La Casa Blanca. (1995). U.S. Policy on Counterterrorism. Washington. Recuperado de www.fas.org/irp/offdocs/pdd39.htm

La Casa Blanca. (1998). Protection Against Unconventional Threats to the Homeland and Americans Overseas. Washington. Recuperado de www. fas.org/irp/offdocs/pdd-62.htm.

Lawless vs. Irlanda. (1960, noviembre 14). Tribunal Europeo de Derechos Humanos.

Lilian Celiberti de Casariego vs. Uruguay. (1981, julio 29). Comunicación $\mathrm{N}^{\circ}$ R.13/56. Comité de Derechos Humanos. Recuperado de Nadelmann, E. (1993). The evolution of United States Involvement in the International Rendition of Fugitive Criminals. New York University Journal of International Law and Policy, 25, 813-885.

Loizidou vs. Turquía. (1995, marzo 23). Objecciones preliminares. Tribunal Europeo de Derechos Humanos.

Loizidou vs. Turquía. (1996, diciembre 18). Sentencia. Tribunal Europeo de Derechos Humanos.

Luluyev y otros vs. Rusia (2006, noviembre 9). Tribunal Europeo de Derechos Humanos.

Mamatkulov y Askarov vs. Turquía. (2005, febrero 4). Tribunal Europeo de Derechos Humanos.

McKenzie et al. (Jamaica), (2000, abril 13). Comisión Interamericana de Derechos Humanos.

Murphy, P. (2007). Intelligence and Security Committee Rendition. Recuperado de http:/ / www.fas.org/irp/world/uk/rendition.pdf. 
Nino, M. (2008). Extraordinary renditions: The Role of European Security Services in the Fight against International Terrorism. Electronic Review of the International Association of Penal Law, 78.

Nikos, T. (2011). Präventive Freiheitsentziehungen als Instrument der Terrorismusbekämpfung. Berlin: Duncker \& Humblot.

Öcalan vs. Turquía. (2005, mayo 12). Sentencia. Tribunal Europeo de Derechos Humanos.

Organización de las Naciones Unidas. (2004). General Comments adopted by the Committee for Human Rights: The Nature of the General Legal Obligation Imposed on States Parties to the Covenant (General comment $N^{\circ} 31$ ).

Posl, M. (2011). Die Sicherungsverwahrung im Fokus von BVerfG, EGMR und BGH. Zeitschrift für das Juristische Studium, 4, 132-146.

Satterthwaite, M. (2007). Rendered Meaningless: Extraordinary Rendition and the Rule of Law. The George Washington Law Review, 75 (5-6), 13331420.

Soering vs. Reino Unido. (1989, julio 7). Tribunal Europeo de Derechos Humanos.

Sottiaux, S. (2008). Terrorism and the limitations of Right: The ECHR and the US Constitution. Oxford: Hart Publishing.

Stark, R. (1993). The Ker-Frisbie-Alvarez Doctrine: International Law, Due Process, and United States Sponsored Kidnapping of Foreign Nationals Abroad. Connecticut Journal of International Law, 9(1), 113-163.

Smet, S. (2012). Othman (Abu Qatada) vs. the United Kingdom: Questioning Gäfgen? Recuperado de: http://strasbourgobservers. com/2012/02/08/othman-abu-qatada-v-the-united-kingdomquestioning-gafgen/

Stocké vs. Alemania. (1989, octubre 12). Sentencia. Tribunal Europeo de Derechos Humanos.

Unión Europea. (2000). Carta de los Derechos Fundamentales de la Unión Europea.

Vermeulen, ML. (2012). Enforced Disappearance: Determining State Responsibility under the International Convention for the Protection of All Persons from Enforced Disappearance. Intersentia.

Yoo, J. (2003).Transferring Terrorists. Notre Dame Law Review, 79, 1183-1235. 